\title{
Development of a clinical Multiple-Lunge test to predict falls in older adults
}

\author{
Ruth Wagenaar
}

A thesis submitted to Auckland University of Technology in partial fulfilment of the requirements for the degree of Master of Health Science

February 2010

School of Sport and Recreation

Primary Supervisor: Justin Keogh 


\section{Contents}

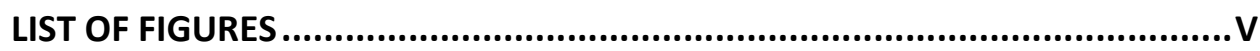

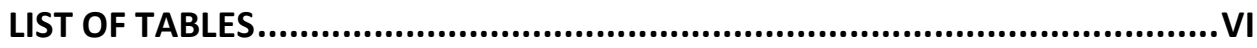

LIST OF APPENDICES ...............................................................................

DECLARATION ....................................................................................

ACKNOWLEDGEMENTS....................................................................

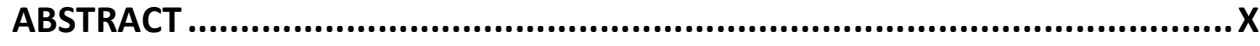

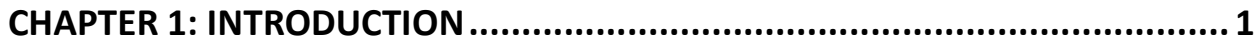

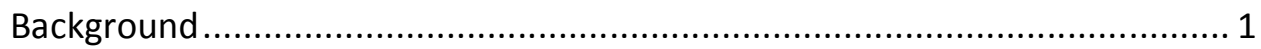

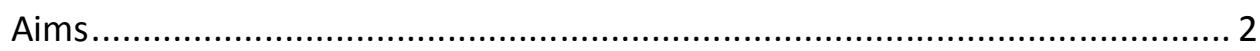

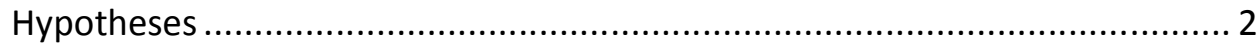

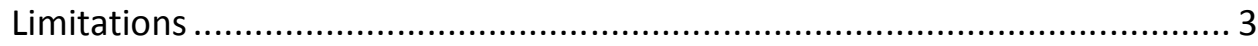

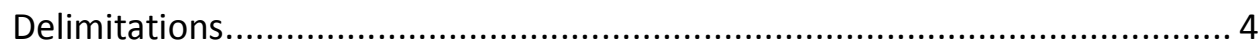

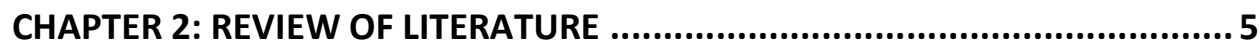

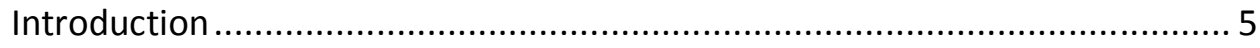

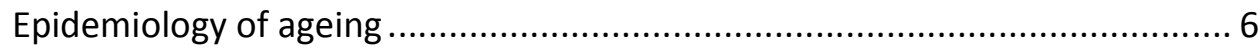

Incidence of falls ....................................................................... 6

The consequences of falls ............................................................ 8

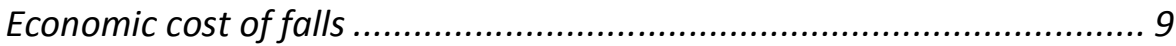

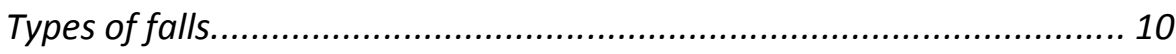

Causes and risk factors of falls..................................................... 11

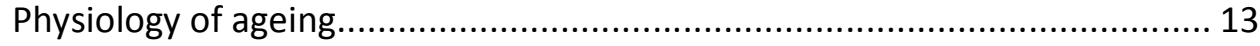

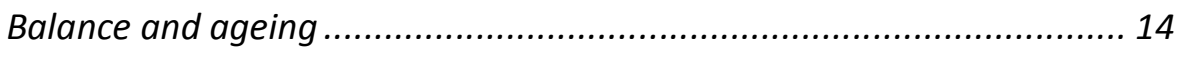

Muscular strength, power and ageing ......................................... 17

Neural function and ageing ....................................................... 17

Cardiovascular changes with ageing............................................ 18

Biomechanics of gait and falls ......................................................... 19

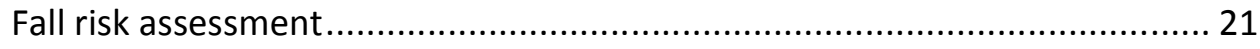

Tinetti Performance Orientated Mobility Assessment ......................... 26 


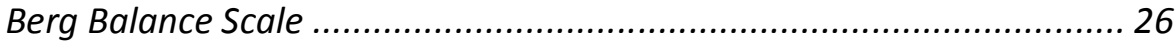

Dynamic Functional Reach test.......................................................... 27

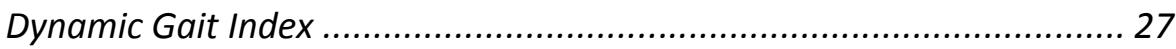

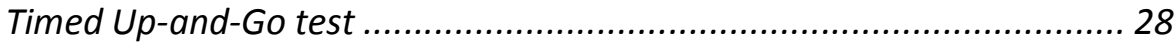

Five Times Sit-to-Stand test ............................................................. 28

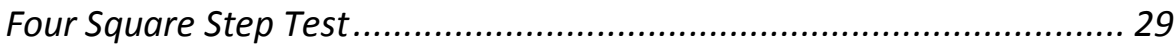

Summary of falls-risk assessment tools............................................... 29

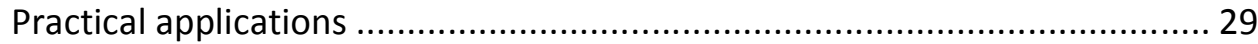

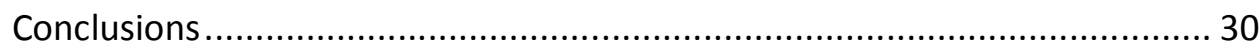

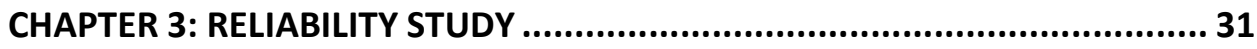

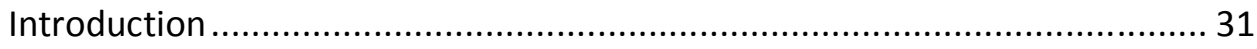

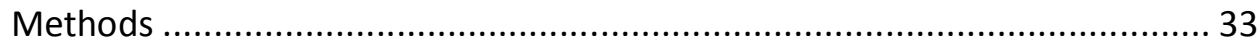

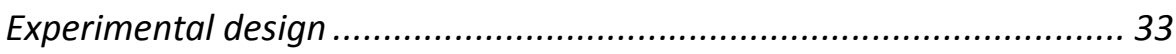

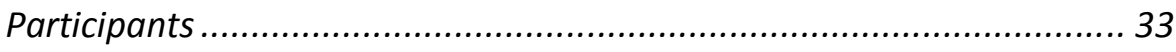

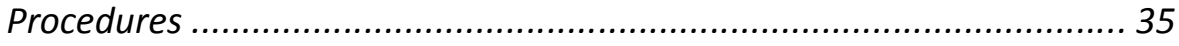

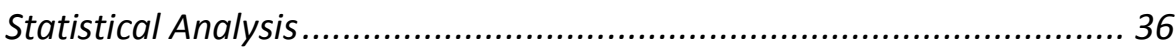

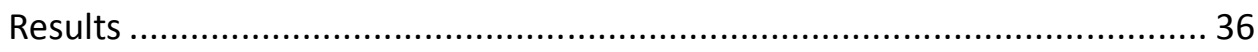

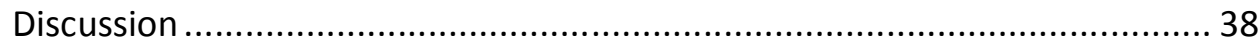

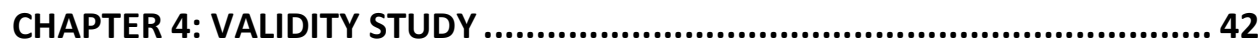

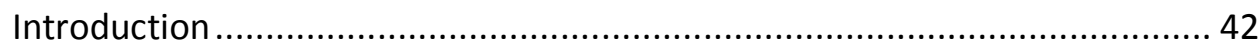

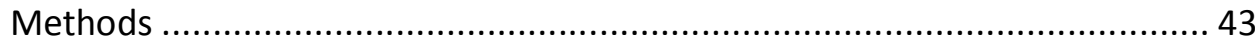

Experimental design ...................................................................... 43

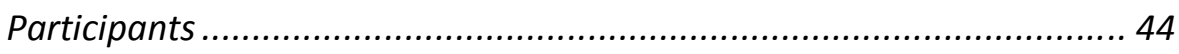

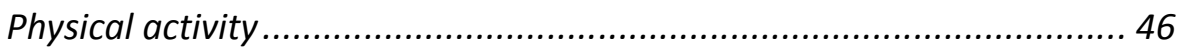

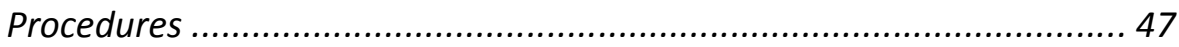

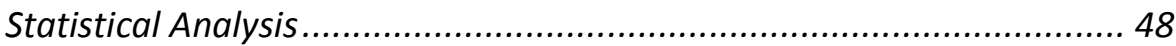

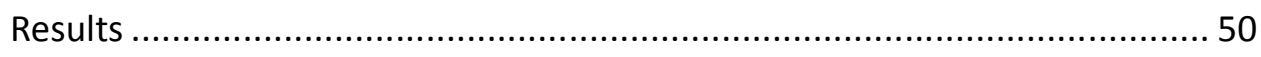

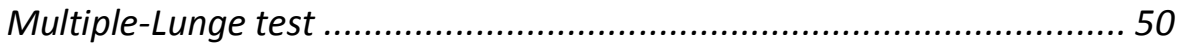

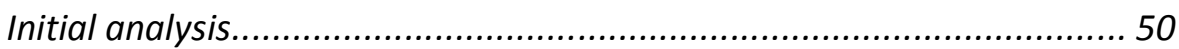

Linear regression analysis........................................................ 52

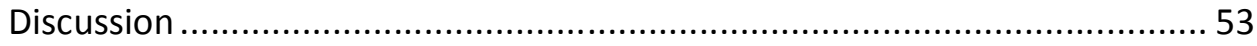




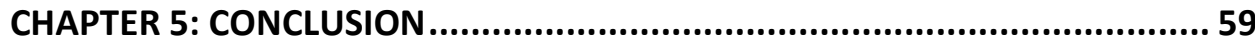

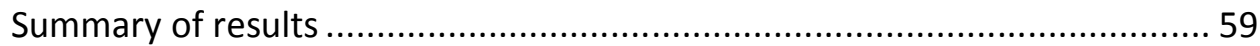

Characteristics of fall risk assessment tools ...................................... 59

Experiment 1: reliability study ..................................................... 59

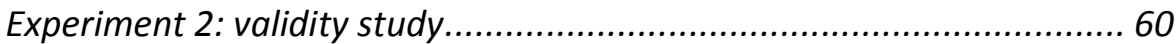

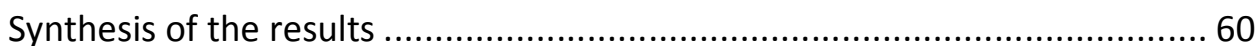

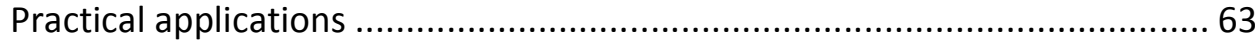

Recommendations for future research..............................................63 63

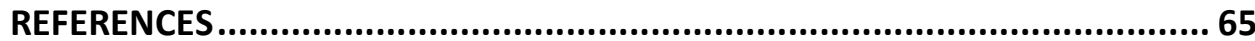




\section{LIST OF FIGURES}

Figure 1: Risk factors for falls................................................................ 12

Figure 2: Fall status - reliability study ................................................ 34

Figure 3: Fall status of 130 participants ................................................. 45

Figure 4: A two by two, or 'truth' table to calculate predictive properties of an assessment tool, adapted from Davidson (2002)........................ 49

Figure 5: Percentage of Non-fallers and Fallers and the number of steps performed correctly from five steps ........................................ 50

Figure 6: Percentage of Single-fallers and Multiple-fallers and the number of steps performed correctly from five steps................................ 51 


\section{LIST OF TABLES}

Table 1: Incidence of falls among community dwelling elderly 7

Table 2: Rationale for falls prediction test selection, adapted from Lord et al. (2007) 22

Table 3: Common fall-risk assessment tools in relation to criteria by Lord et al. (2007) 25

Table 5: Participant characteristics of reliability study subjects $(n=14)$........ 34

Table 6: Leg length results for test 1 and test 2 .................................. 36

Table 7: Means and standard deviations for number of correct steps (out of

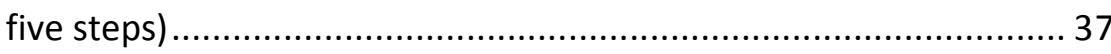

Table 8: Reliability for number of correct steps (out of five steps) 37

Table 9: Means and standard deviations for total Multiple-Lunge test time . 37

Table 10: Reliability of total time to complete the Multiple-Lunge test ........ 38

Table 11: Subject characteristics of 130 older adults ..... 44

Table 12: Reasons for falls as reported retrospectively by forty older adults with a history of falls. 46

Table 13: Subject physical activity categories by group 46

Table 14: Subject participation in strength and flexibility activities by group 47

Table 15: Definitions and calculations of test characteristics, adapted from Davison (2002)

Table 16: Sensitivity, specificity, predictive values, accuracy and prevalence values for Multiple-Lunge test by number of correct steps 51

Table 17: Sensitivity and specificity values for different variables as determined using predicted fall values from linear regression analysis 52

Table 18: Linear regression predictors of falls; Fallers vs. Non-fallers . 53 


\section{LIST OF APPENDICES}

Appendix 1: Ethics approval, Auckland University of Technology Ethics

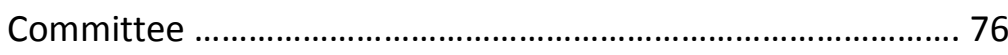

Appendix 2: Participant information sheet ................................................. 78

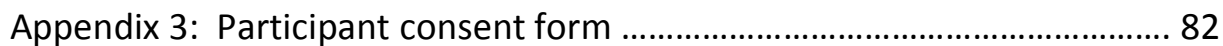

Appendix 4: Modified Physical Activity Readiness Questionnaire ............... 83

Appendix 5: Falls History Questionnaire ......................................................85

Appendix 6: Rapid Assessment of Physical Activity (RAPA) Questionnaire. 86

Appendix 7: Truth tables for Chapter 3, Validity study. Comparison 1:

Percentage of participants with zero out of five steps done

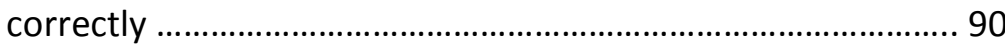

Appendix 8: Truth tables for Chapter 3, Validity study. Comparison 2:

Percentage of participants with five out of five steps done correctly 


\section{DECLARATION}

I hereby declare that this submission is my own work and that, to the best of my knowledge and belief, it contains no material previously published or written by another person (except where explicitly defined in the acknowledgements), nor material which to a substantial extent has been submitted for the award of any other degree or diploma of a university or other institution of higher learning.

Signed

Date 


\section{ACKNOWLEDGEMENTS}

I wish to acknowledge the support and advice given to me by my supervisors Associate Professors Justin Keogh and Denise Taylor. As an international student I was greatly assisted by Justin throughout the two years of my Masters, including aspects such as finding a job and making friends. Justin was always happy for me to turn up at his office with questions and I am very grateful for his time and effort. Thank you to Will Hopkins, for his enthusiastic advice on statistical analysis and for his informative website Sportscience, which I spent much time examining. Many thanks also to Professor John Cronin and Dr Ineke Crezee for their time spent proof reading.

Ethics approval, number 09/93 was obtained from AUTEC on 23 June 2009. For the research assistance I had with some of the testing sessions, I would like to thank Deborah MacRae and Jolanthe de Koning. Their manner was always professional and pleasant and I wish them all the best in their future studies. I would also like to acknowledge the School of Sport and Recreation, AUT University for providing funding for the research assistants which were crucial to the safety of this project.

I am so grateful to all the willing participants in my study, for without them this research would not be possible. I hope the study helped to gain an insight into your own abilities. With further help from volunteers like you we will continue to work towards reducing the nasty incidence of falls.

I wish to acknowledge my parents, for encouraging me to strive for the best in all my endeavours. The values you have instilled me have stood me in good stead. To Amber and Jason, my good friends and house-mates, thank you for your understanding through my ups and downs, you have both been a blessing in my life.

To my husband Strini, who has motivated me consistently throughout my studies, thank you for your unwavering confidence in me. You are the love of my life and my best friend, and this thesis would not have been possible without your support. 


\begin{abstract}
Background: The incidence of falls and severity of fall related injuries steadily increase with age. As well as physical injury, falls can lead to adverse psychological and social consequences, which can further reduce older adults' quality of life. The most commonly reported cause of falls in older persons is tripping over an obstacle, which may reflect the difficulty many older adults have in making an appropriate stepping response. In order to reduce the number of falls experienced by older adults, individuals at high risk of falling need to be identified so that targeted interventions can be implemented.
\end{abstract}

Aims: This series of studies aimed to develop a new Multiple-Lunge test to distinguish between Fallers and Non-fallers in independent older adults, aged 65 years and over. The studies sought to determine the test-retest reliability of the Multiple-Lunge test; as well its validity to predict faller status in a sample of community-dwelling older adults.

Methods: One hundred and thirty community-dwelling older adults, aged 65 93 years (mean age $77 \pm 7$ years) with $(n=40)$ and without $(n=90)$ a history of falls were administered the Multiple-Lunge test. For the purpose of this study, a Faller was classified as an older adult with a history of one fall, or a Multiple-faller if there was a history of two or more falls in the previous 12 months. The Multiple-Lunge test required the individual to lunge forward to a step length determined as $60 \%$ of their leg length, and return to start position, for a total of five repetitions. Two trials were performed after a familiarisation trial. The number of correct steps and the total time for the five steps were recorded for each trial. The highest number of correct steps and the lowest total time of the two trials were used for data analysis. Test-retest reliability of the Multiple-Lunge test was established across two testing occasions from a sub-sample of the validity study ( $n=14$, mean age $79 \pm 6$ years). A crosssectional design was used to establish the sensitivity and specificity of the 
Multiple-Lunge test to predict faller status based on retrospective selfreported fall history. Initial analysis using the number of correct steps and total time, was followed by a linear regression analysis to determine the validity of the test to predict falls.

Results: The Multiple-Lunge test was found to be reliable across trials (ICC $=$ 0.79 for number of correct steps; ICC $=0.86$ for total time). The change in the mean for steps was small and similar across four trials (-0.43 steps, -0.36 steps, -0.50 steps). The change in the mean for time showed a gradual decrease in time scores across trials $(-0.69$ seconds, -0.73 seconds, -0.93 seconds). Sensitivity and specificity values were calculated as $73 \%$ and $63 \%$ for predicting Multiple-fallers using the measure of all five steps done correctly. Linear regression analysis did not indicate that the Multiple-Lunge test could be used to predict faller status for either of the step predictor variables $(0 / 5$ steps or $5 / 5$ steps). However, a very high sensitivity value (98\%) was observed for the variable of both steps and time in predicting Fallers. Also a very high specificity value (99\%) was recorded for the variable of time to predict Multiple-fallers.

Conclusions: The Multiple-Lunge test is an easily administered test for independent older adults. Due to the challenging nature of the test it may be well suited to detect subtle differences in abilities of higher functioning older adults. The test mimics the movements needed in response to a trip, the most common cause of falls in older adults. This test is a reliable and reasonably valid measure of falls risk. A practitioner can be confident in 7 out of 10 cases that an older adult who cannot complete all five steps of the Multiple-Lunge test is at high risk of falls. The results of this thesis suggest that there is potential for the Multiple-Lunge test to be used in clinical practice and fall prevention research. However, additional research on how to further increase its validity and/or to determine the most appropriate populations with which to administer this test appears warranted. 


\section{CHAPTER 1: INTRODUCTION}

\section{Background}

There has been a rapid increase in the adult population 65 years and older in many developed countries like New Zealand in the last ten years, with further increases expected (Statistics New Zealand, 2009). An understanding of the issues associated with ageing is therefore necessary. One of the most detrimental effects of ageing is falls (Lord, Sherrington, Menz, \& Close, 2007). Approximately $30 \%$ of adults over the age of 65 fall at least once per year, and up to $30 \%$ of those falls result in moderate to severe injuries which negatively affect functional ability and hence quality of life (Hausdorff, Rios, \& Edelberg, 2001). Falls can occur due to many factors, but the majority of older adults who suffer falls cite tripping over obstacles as the reason for falling (W. P. Berg, Alessio, Mills, \& Tong, 1997; Lord, Ward, Williams, \& Anstey, 1993). The high incidence of trip related falls has been linked to decreases in balance, reaction speed, and strength in older age (Pijnappels, Reeves, Maganaris, \& Van Dieën, 2008).

A key concern in falls prevention has been the development of accurate assessment tools to predict those at risk of falling. Use of quick, valid and reliable fall risk screens are required to identify high-risk individuals (Rose, Lucchese, \& Wiersma, 2003). Specific intervention programs which target deficits of balance, strength and/or coordination can then be implemented.

There are many tests available for assessing the functional abilities of older people. Current tests are less accurate at predicting fall risk in active older adults than in more frail and older populations (Boulgarides, McGinty, Willett, \& Barnes, 2003). Among the most common tools, the Berg Balance Scale was found to have ceiling effects in more active older adults (Muir, Berg, Chesworth, \& Speechley, 2008); the Timed-Up-and-Go test was found to be less predictive of falls in younger older adults (Shumway-Cook, Brauer, \& 
Woollacott, 2000); and the Five Times Sit-to-Stand test was not a powerful predictor when used as a stand-alone measure (Tiedemann, Shimada, Sherrington, Murray, \& Lord, 2008). The need for the development and testing of new assessment tools which may uncover functional deficits of higher functioning populations of older adults is therefore warranted. These tests should place more challenging demands on the individual. Any individuals at risk can then be prescribed specific programmes which may improve weaknesses, in balance and strength for example, and thus reduce their risk of falls.

The movements required for recovery of a trip in preventing a fall are similar to a lunge type movement, which requires a larger step than normal to counter the effects of angular momentum pushing the body forward. Also, the support leg needs to produce large amounts of force to maintain balance. A Multiple-Lunge test which is physically demanding and would appear to stimulate many aspects of trip recovery may be able to uncover weaknesses in higher functioning older adults and hence be useful as a falls assessment tool. The Multiple-Lunge test is a new test developed for this thesis which is examined in the following chapters.

\section{Aims}

1. To determine the test-retest reliability of the Multiple-Lunge test in independent older adults.

2. To determine the validity of the Multiple Lunge test to distinguish between Fallers and Non-fallers in independent older adults.

\section{Hypotheses}

1. The Multiple-Lunge test will have high to excellent test-retest reliability across trials on the same day and between two test days with the same subjects.

2. The Multiple-Lunge test will distinguish between Fallers and Non-fallers based on a retrospective self-report of falls. The individuals with a history 
of falls will present with worse scores on the test than those with no history of falls.

3. The test will be able to distinguish between Multiple-fallers and Nonfallers.

\section{Limitations}

1. Subjects were classified as Fallers or Non-fallers based on retrospective self-report from a 12 month period. This method is less accurate than prospective measures due to the subjects' limited accuracy in remembering falls over a long period (Cummings, Nevitt, \& Kidd, 1988). Due to time constraints it was impossible to pursue a prospective study and emphasis was placed on falls recall when interviewing subjects.

2. Some researchers have suggested that those individuals who have only suffered a single fall should be excluded from analysis which would place them in a Faller group, as these individuals may not be truly representative individuals with a physiologic predisposition to falling (Buchner et al., 1993). The present study has included Single Fallers in the Faller group due to recruitment difficulties.

3. The measurement of leg length for the Multiple-Lunge test was difficult with regards to locating measurement points. The Anterior Superior Iliac Spine (ASIS) was especially difficult to locate on overweight individuals. Care was taken to measure as accurately as possible, while remaining sensitive to the individual.

4. The time recorded for the Multiple-Lunge test was the total time to complete the test, and not split per step. Therefore the time score alone was not truly representative of performance on the test, as a subject with a faster time may not have completed all steps correctly. 


\section{Delimitations}

1. A total of 130 subjects were tested.

2. All subjects were community-dwelling (independent) adults aged 65 years or older. 


\section{CHAPTER 2: REVIEW OF LITERATURE}

\section{Introduction}

Falls in older people present a significant health problem, which affects around $30 \%$ of community dwelling persons over the age of 65 each year (Lord et al., 2007). The most prevalent cause of falling is cited as tripping over an obstacle, which constitutes more than half of the reported falls (W. P. Berg et al., 1997). The impact of falls includes increased morbidity and mortality and health care costs. The 65 and older age group will double in New Zealand in the next 25 years (Statistics New Zealand, 2009) and because of this growth of the older population, and the increase in falls incidence fall prevention is crucial.

The research regarding falls in older adults is vast, and many fall-risk assessment tools have been developed in order to identify individuals at risk of falling (Lord et al., 2007). Some of these tests have been validated only with very frail older adults or those with significant health problems and may not be sensitive to the higher functioning older adult (Rose et al., 2003).

There is a need to develop and evaluate an assessment tool that identifies independent older adults at risk of falls (Keskin et al., 2008). An accurate understanding of individual's strengths and weaknesses allows targeted interventions to be implemented, increasing the likelihood of fall prevention. Assessment tools help to improve understanding, if they are valid and reliable. The possibility of falling may be able to be predicted, and thus programmes can be prescribed to address specific impairments so that falling is reduced. Such a measure may also be used as a tool to evaluate progress following an intervention. 


\section{Epidemiology of ageing}

The definition of an older person has not been clearly established, and some studies may use the term for age groups starting as low as 50 years. Most often the term older person refers to those aged 65 years and over. This demographic group is frequently divided into subgroups, namely $65-74$ years, 75 - 84 years, and 85 years and older (Lord et al., 2007). For the purposes of this review, older person will refer to individuals aged 65 years or older.

\section{Incidence of falls}

A fall is defined as "an event resulting in an individual unintentionally coming to rest on the floor, or other lower level, not as the result of a major intrinsic event or overwhelming hazard" (Tinetti, Speechley, \& Ginter, 1988, p. 1702). Approximately $30 \%$ of elderly individuals over 65 years old, living independently in the community, suffer at least one fall per year (W. P. Berg et al., 1997; Blake et al., 1988; Campbell et al., 1990; Campbell, Reinken, Allan, \& Martinez, 1981; Lord, Clark, \& Webster, 1991; Tinetti, Deleon, Doucette, \& Baker, 1994; Tinetti et al., 1988; Tinetti \& Williams, 1998). The majority of the early studies were retrospective in nature, calling on individuals to recall falls from the last 12 months. The accuracy of these studies is limited in that subjects may not remember all past falls, meaning that retrospective studies are more likely to under-report the true number of falls (Cummings et al., 1988). The design and use of prospective studies has been a more recent practice in which subjects are followed for a period of time, usually 12 months. The more recent studies have reported a higher rate of falling, possibly due to increased accuracy (Lord et al., 2007). A summary of reported literature, of the incidence of falls in community-dwelling elderly is detailed in Table 1. 
Table 1: Incidence of falls among community dwelling elderly

\begin{tabular}{lcccc}
\hline Reference & Age & $\begin{array}{c}\text { Number of } \\
\text { subjects }\end{array}$ & $\begin{array}{c}\text { \% of sample } \\
\text { who fell per } \\
\text { year }\end{array}$ & $\begin{array}{c}\text { \% falls led } \\
\text { to fracture / } \\
\text { serious injury }\end{array}$ \\
\hline RETROSPECTIVE & & & & \\
Campbell et al. 1981 & $>65$ & 533 & 34 & NR \\
Blake et al. 1988 & $>65$ & 1042 & 35 & NR \\
Tinetti et al. 1994 & $>72$ & 1103 & 39 & 14 \\
Stalenhoef et al. 1999 & $>55$ & 96 & 23 & 9 \\
Gill et al. 2005 & $>65$ & 2619 & 30 & NR \\
& & & & 24 \\
PROSPECTIVE & $>75$ & 336 & 32 & 24 \\
Tinetti et al. 1988 & $>70$ & 684 & 35 & NR \\
Campbell et al. 1990 & $>65$ & 341 & 39 & 14 \\
Lord et al. 1994 & $>60$ & 96 & 52 & 4 \\
Berg et al. 1997 & $>71$ & 885 & 30 & \\
Tinetti et al. 1998 & & & & \\
\hline NR data not reported & & & & \\
\hline
\end{tabular}

$\mathrm{NR}=$ data not reported

A study conducted in New Zealand by Campbell et al. (1981) recorded falls over 1 year for 533 subjects, aged 65 years and older. Of these 34\% reported at least one fall over the time period. The study showed that as age increased so did the rate of falls; $45 \%$ of those aged 80 - 89 years experienced falls, while $56 \%$ of those aged 90 - 99 years had fallen in the last year. A later study by Campbell et al. (1990) showed a slight increase in falls incidence (35\%) compared to other studies, and this has been attributed to the prospective nature of the study, as well as the inclusion of subjects living in residential homes ( $6 \%$ of sample). Also the age of the subjects ( $>70$ years) was older than in other studies.

Berg et al. (1997) reported a much higher fall rate (52\%) than the rest of the literature. The proposed reason has been the volunteer sample and small sample size of only 96 individuals, which may not accurately represent the community-dwelling elderly population as a whole. Berg et al. (1997) thought that active individuals may have volunteered for the study more than frail individuals. Moreover, it may be that those who are more active are presented with more occasions for falling, and therefore have a higher falls 
incidence. However the relationship between physical activity and falls risk is a complex one, which will be considered in upcoming chapters. Conversely, the low incidence (25\%) reported by Stalenhoef et al. (1999) may be due to the small sample size, as well as the inclusion of adults aged 55 years upward, which is younger than that of the subjects in the other studies. When the 65 years and older group was isolated the percentage of fallers rose to $31 \%$, which is more consistent with the literature.

A study by Campbell et al. (1990) found that the majority of falls are generally a result of falling over normal, uncluttered objects, such as chair legs and footrests rather than what would be considered hazardous objects. Within the home falls occur in the most frequently used rooms, such as the bedroom, lounge and dining room, but surprisingly the presence of stairs at home does not seem to increase the risk of falls (Stalenhoef et al., 1999). Besides, falls at home occur more often outdoors than indoors (W. P. Berg et al., 1997), and men fall outside more than women, especially during physical activity, such as gardening (Campbell et al., 1990). In general however, women sustain more falls than men (Stalenhoef et al., 1999), at a ratio of approximately 2.7:1 (Blake et al., 1988).

\section{The consequences of falls}

Falls in older adults can be injurious and lead to further complications. Tinetti et al. (1988) found that $25 \%$ of falls lead to serious injury, including soft tissue injury and fractures, and that $25 \%$ of falls lead to subsequent restrictions in activities of daily living (ADL). Fractures which may occur as a result of falls put one at risk of further falls and loss of functioning (W. P. Berg et al., 1997; Stalenhoef et al., 1999). The most serious fall-related injury in older people is fracture of the hip, in that recovery is slow and post-operative complications are relatively common (Stalenhoef et al., 1999). Also, hip fractures lead to a substantial decline in physical function, as concluded in a 6 month prospective study by Marottoli (1992). 
Another dangerous consequence of falling is the 'long lie', which refers to remaining on the ground for longer than an hour after a fall (Lord et al., 2007, p. 16). The long lie is associated with weakness, illness and high mortality rates in older people. In one study it was found that half of those who suffer a long lie die within six months, even if the fall resulted in no direct injury (Wild, Nayak, \& Isaacs, 1981). An early study found that $20 \%$ of patients admitted to hospital as a result of a fall had suffered a long lie (Vellas, Cayla, Bocquet, Depemille, \& Albarede, 1987). Because they were hospital admissions this sample probably only represented very frail or injured fallers. More recent studies have established that only $10 \%$ of falls resulted in a lie of longer than one hour (Campbell et al., 1990; Nevitt, Cummings, \& Hudes, 1991). Even so, the significance of the long lie is relevant when considering the fact that $47 \%$ of non-injured fallers are unable to stand after falling without assistance (Tinetti, Liu, \& Claus, 1993). This is especially important for those individuals who live alone, or spend much of their time alone.

Falls have also been related to a decrease in individual self-confidence. A study by Tinetti et al. (1994) confirmed that $43 \%$ of community-dwelling older adults report a fear of falling, which may lead to activity restriction, decrease in social interactions and an increased risk of falling (Friedman, Munoz, West, Rubin, \& Fried, 2002). Future falls prevention interventions in older adults should strive to improve self efficacy, through personal accomplishment, vicarious experience, verbal persuasion and physiologic states, as theorised by Bandura (1977), in that performance is determined by perceived as well as actual capability for a task.

\section{Economic cost of falls}

Fall related injuries in older adults are associated with considerable economic costs. The costs include medical, rehabilitation and hospital costs, as well as the costs of morbidity and mortality (Robertson et al., 2001). The costs borne by society as a result of fall injuries will continue to increase with increasing age. Data from the United States showed that direct medical costs 
totaled $\$ 0.2$ billion for fatal, and $\$ 19$ billion for non-fatal fall-related injuries in the year 2000 for older adults over 65 years (Stevens, Corso, Finkelstein, \& Miller, 2006). Of the non-fatal injury cost $63 \%$ were for hospitalisations, $21 \%$ for emergency department visits, while $16 \%$ were for treatment in the outpatient setting. Fractures were the most common fall-related injury, and the most expensive type of injury (Stevens et al., 2006).

No current statistics exist for New Zealand with regards to the economic cost of falls specifically. However, data outlining total health expenditure was available. For example, the estimated per capita expenditure for people under the age of 15 in 2001 was $\$ 949$, compared with $\$ 3643$ for people aged 65 - 74 years, $\$ 6863$ for people aged 75 - 84, and $\$ 13,568$ for people aged 85 and over (New Zealand Ministry of Health, 2002). Of all hospital admissions, over $32 \%$ were for the $12 \%$ of people aged 65 and over. Hospitalisation rates for older people increase with age with much higher rates for people aged 85 and over than for people aged 65 - 74 (New Zealand Ministry of Health, 2002). With respect to falls, data from New Zealand in the years between 1993 and 2002 show that 55\% of all hospitalised unintentional injuries were as a result of falls, in people aged 65 to 69 years old. In those aged 70 to 74 years this percentage rose to $65 \%$, and the figure was even higher in those aged 75 and older, where $85 \%$ of hospitalised injuries were due to falls (Accident Compensation Corporation, 2005). Methods to predict fallers and the development of interventions that prevent falls in older adults would appear a priority to reduce the incidence of falls, which would likely result in a reduction in health care costs, in addition to improving the quality of life of older adults.

\section{Types of falls}

Although older adults fall due to a variety of reasons, the most common cause of a fall is a trip, which accounts for up to $60 \%$ of falls in adults over 65 years (W. P. Berg et al., 1997; Blake et al., 1988; Lord et al., 2007). A trip occurs when one stumbles over an obstacle with their feet, and results in 
a fall when the individual is unable to recover their balance. This occurs on both uneven and even surfaces and has been attributed to hurrying. After tripping, the older adult needs to make a quick reaction to minimise the chance of falling (Campbell et al., 1990). In most cases the obstacle which causes the trip is minor, but the adjustment, reaction speed and muscular strength and power needed to overcome a fall is too great for the individual to achieve (Pijnappels, Van der Burg, Reeves, \& Van Dieën, 2008).

Reasons for increased falls in older compared to young people may be because they trip more often, or because they are unable to regain their balance after a trip. The likelihood of tripping depends on the presence of obstacles, the individual's gait and their ability to detect and avoid or compensate for the obstacle. The literature does not show that older people as a group are more likely to trip than young people, however the likelihood of recovering from a trip is significantly lower in older adults (Pijnappels, Reeves et al., 2008).

The high prevalence of falls as cited in older adults has many negative consequences, including reduced quality of life and risk of further falls, as well as an economic burden to society. Therefore work with the older adult population should aim to reduce the incidence of falls and if possible prevent their occurrence. Prevention is enhanced by an understanding of individual strengths and weaknesses, so that targeted interventions can be implemented. Assessment tools help to improve understanding, if they are valid and reliable. The possibility of falling may be able to be predicted and thus programmes can be prescribed to address specific impairments so that falling is reduced.

\section{Causes and risk factors of falls}

Various risk factors have been related to falls in the elderly and many causes of falls have been found. Risk factors for falls are older age, a history of falls, functional impairment, walking aid use, cognitive impairment or dementia, impaired mobility or low activity level and balance impairment 
(Inouye, Studenski, Tinetti, \& Kuchel, 2007). The multi-factorial nature of falls is depicted in Figure 1. Fall risk increases with an increase in age (Blake et al., 1988; Campbell et al., 1981; Lord, Ward, Williams, \& Anstey, 1994), is greater in women than men (Blake et al., 1988; Stalenhoef et al., 1999) and is increased by disorders of gait, poor vision and balance problems (Blake et al., 1988; Campbell et al., 1981; Lord et al., 1991; Stalenhoef et al., 1999; Tinetti et al., 1988).

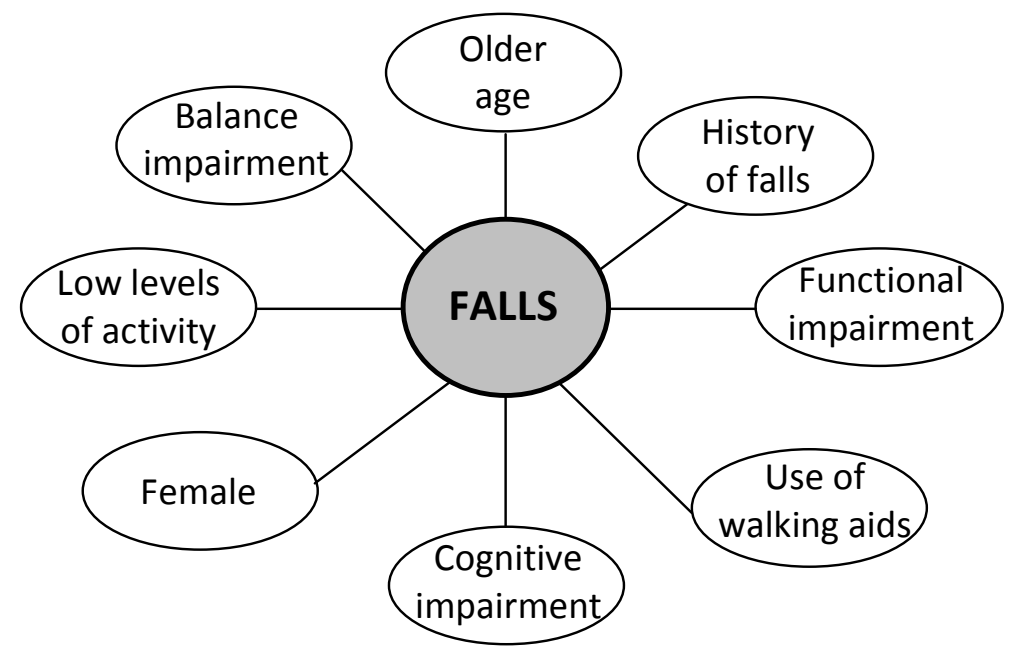

Figure 1: Risk factors for falls

In a recent study with community dwelling adults over 65 years old who had been hospitalised due to a fall resulting in a hip fracture; $53.5 \%$ reported at least one fall in the six months following hospitalisation (Shumway-Cook, Ciol, Gruber, \& Robinson, 2005). Also, these individuals were less independent in activities of daily living, and had lower balance and mobility capabilities than before they sustained the fracture. The implications of a single fall are therefore important with regards to the risk of future falls, and signify the need for fall prevention interventions and/or strategies. Berg et al. (1997) noted that falls are more likely to occur in the home, than away, with outdoor falls being more prevalent than indoor falls. This research also found that the majority of falls occur when the individual is alone. Campbell et 
al. (1990) stated that falls occur during periods of maximum activity, usually the morning and afternoon. Highly active individuals often experience a higher incidence of falls than those who are less active or sedentary (W. P. Berg et al., 1997). The extremes of activity may be the likely cause of falls, in that vigorous activity presents greater occasion for falling (Gill, Taylor, \& Pengelly, 2005). In contrast to the above Lord et al. (1993) found that those individuals participating in physical activity or exercise at least seven hours a week, experience significantly fewer falls than those who are less active. This may be due to the maintenance of fitness and stability which minimises fall risk; or it could mean that those with poor balance and mobility are limited in their physical activity pursuits, meaning that they are not at high risk of falls as they rarely stand, let alone walk for any period of time.

The literature reviewed indicates that falls occur often in older adults, with the consequence of falls being very serious on many occasions, as well as being costly. Prevention of falls may help to delay the negative effects associated with falling. Research and development of appropriate assessment measures is of critical importance to allow identification of older adults at risk of falling (Lord et al., 2007), so that targeted intervention strategies can be developed, tested and if successful, administered. In order to do this effectively it is important to first be aware of the causes of falls as outlined above. Thereafter, an understanding of the effects of ageing and the physiology of ageing is essential.

\section{Physiology of ageing}

Throughout childhood physiologic function develops greatly, and reaches a maximum between late adolescence and 30 years of age. Functional capacity decreases thereafter, depending on one's lifestyle (McArdle, Katch, \& Katch, 2001). The physiologic decline with age does not occur at the same rate across all systems. Between 30 - 80 years, for example, nerve conduction velocity decreases by only 10 - 15\%, but by the age of 80 maximum breathing capacity is approximately only $40 \%$ of that at age 30 (McArdle et al., 2001). 
Some functions at rest may show little difference regardless of age, such as heart rate, but significant changes are evident during maximal exercise. Regular exercise has been shown to counter the effects of physiologic decline with age. For example, an active 50 year old has a $25 \%$ greater aerobic capacity than a sedentary 20 year old, thereby maintaining the functional level of a younger individual (McArdle et al., 2001). For this reason one of the current foci in gerontology is to promote successful ageing through encouraging increased physical activity in the lives of older individuals. The physiologic decline associated with ageing has been linked to increased risk of falls and fall injuries (Topinkova, 2008). This decline is the result of collective physiologic changes as discussed below.

\section{Balance and ageing}

Most activities of daily life depend largely on the ability of an individual to balance themselves. Good balance requires the successful integration of sensory information regarding the position of the body in relation to the surroundings, and the ability to generate appropriate motor responses to control body movement (Sturnieks, St George, \& Lord, 2008). Often referred to as a 'systems model', balance relies on contributions from vision, vestibular sense, proprioception, muscle strength and reaction time. There is significant evidence that with age there is a decline in these sensorimotor factors which contribute to balance control (Lord et al., 2007).

Vision deteriorates from the age of 50 , with decreases in visual processes such as visual acuity, contrast sensitivity, glare sensitivity, dark adaptation, accommodation and depth perception all apparent (Gittings \& Fozard, 1986). Furthermore, older people are at risk of developing visual problems from common eye pathologies such as cataracts, macular degeneration and glaucoma (Sturnieks et al., 2008). Because of these deficits many older adults frequently misjudge distances or spatial information which results in an inability to avoid obstacles and control balance (Lord, 2006). 
The vestibular system detects the position and motion of the head and by using information from the vestibulo-ocular and vestibular-spinal pathways is able to make corrective movements which keep the head and neck in the vertical position, and contribute to balance control (Lord et al., 2007). Research indicates that vestibular function decreases with age (Fife \& Baloh, 1993). Some studies have not found a causal relationship between vestibular deficits and falls in older adults, but this may be due to insensitivity of screening measures to assess vestibular function (Sturnieks et al., 2008). Studies which made use of more accurate measurements of vestibular function verified that impaired vestibular function does increase the risk of falls and fall injuries in older people (Di Fabio, Emasithi, Greany, \& Paul, 2001)

Proprioception refers to the collective functions of joint position sense and movement. These functions are elicited by sensory information from receptors in the muscles, tendons and joints, and are cited as the most important factors to standing balance (Fitzpatrick \& McCloskey, 1994). Effective proprioception contributes to coordination of steps and correct foot placement. Loss of peripheral sensation can be caused by a wide number of causes, including conditions common in older age, such as degeneration of the cervical spine and arthritis (Sturnieks et al., 2008). Also, the number of receptors which provide feedback for tactile information decrease with age, causing reduced sensory information on force distribution from the soles of the feet, resulting in impaired standing balance control (Menz, Morris, \& Lord, 2005). Comprehensive assessments by Lord et al. (1992) reported that reduced proprioception is a consequence of normal ageing, which adversely affects balance and therefore is a risk factor for falls.

Muscle strength has been shown to decrease with age (as detailed below), but the importance with regards to balance is that the rate of torque development as well as peak toque production both decline with age (Thelen, Schultz, Alexander, \& AshtonMiller, 1996). Both these components are required for stepping to recover from disturbed balance, as in a trip (Pearson, Bassey, \& Bendall, 1985). Older adults are therefore at greater risk of reduced balance compared to younger adults, due to differences in muscle strengths 
and speeds of muscle contraction (Sturnieks et al., 2008). Physical activity through later life results in maintenance of muscle mass and function, suggesting that balance deficits of ageing may also be offset by maintaining an active lifestyle (American Geriatrics Society, British Geriatrics Society, \& American Academy of Orthopaedic Surgeons Panel on Falls Prevention, 2001; Orr et al., 2006).

Response time is crucial for the prevention of a fall, especially after tripping. The ability to react quickly and appropriately allows balance to be maintained following a external perturbation and thus for a fall to be prevented (Sturnieks et al., 2008). Between the ages of $20-60$ years reaction time increases by $25 \%$ with increased worsening after this age (Fozard, Vercruyssen, Reynolds, Hancock, \& Quilter, 1994). The slower reaction times evident in older age may be due to changes in the central and peripheral nervous system (Sturnieks et al., 2008). The slowing of reaction time associated with age becomes more considerable during difficult cognitive tasks and more complex movements such as stepping. The stepping movement required after tripping over an obstacle needs to be executed rapidly to avoid falling. Increased reaction time may therefore be a risk factor for falls in older adults.

As outlined above, balance is a function of a combination of variables, namely vision, vestibular, proprioception, muscle strength and reaction time. Balance disorders are evident in poor performance in standing, leaning, stepping, walking, responding to an external perturbation and mobility tasks (Sturnieks et al., 2008). Therefore insufficient balance is likely to be highly related to falls as a result of tripping, in that the individual is unable to recover from the perturbation. There is evidence to suggest that specific exercises may improve balance and thus reduce falls risk (Low, Ang, Goh, \& Chew, 2009; Voukelatos, Cumming, Lord, \& Rissel, 2007). 


\section{Muscular strength, power and ageing}

Strength levels are highest when the cross-sectional area of the muscle is at its largest, generally between the ages of $20-40$ years in men and women. The strength of most muscle groups slowly decreases with age, and quicker after middle age (Taylor \& Johnson, 2008). This degenerative loss of skeletal muscle mass and strength associated with ageing is termed sarcopenia. Decreases in eccentric strength occur at a later age and at a slower rate than concentric strength, while strength losses occur later in women than in men (Frontera, Hughes, Lutz, \& Evans, 1991). In both men and women leg strength deteriorates more rapidly than arm strength, calculated by peak torque per unit muscle mass (McArdle et al., 2001).

Strength measures have been used to identify older individuals at risk of falling (Pijnappels, Van der Burg et al., 2008), especially measures of leg strength which may help in recovering from a trip. The strength loss experienced with age correlates with weight loss, and an increase in chronic diseases, such as stroke, diabetes and coronary heart disease. The ability to generate power declines more rapidly than that for maximum strength, as power is a product of force (strength) and velocity (speed) (Hazell, Kenno, \& Jakobi, 2007). Although performance of daily activities may not require large strength capacities, a certain threshold of power as well as strength appear necessary to perform these activities (Pijnappels, Van der Burg et al., 2008). Consequently, it would appear that in order to recover balance during the late stages of an impending fall the weaker older adult may not be able to produce the required level of force within the short time period available.

\section{Neural function and ageing}

Ageing affects the function of the central nervous system through a decrease of almost $40 \%$ in the number of spinal cord axons, and $10 \%$ in nerve conduction velocity (McArdle et al., 2001). Tests which assess reaction and movement times illustrate the changes in neuromuscular function. Although each change may be small, the combination of the overall deficit of the neural 
system increases the risk of inefficient or ineffective responses, which are especially important in recovering from a trip to prevent a fall (Taylor \& Johnson, 2008). Older individuals move considerably slower in simple and complex tasks, than younger individuals; however, more active older individuals may move significantly faster than their sedentary counterparts and even younger, sedentary individuals (Taylor \& Johnson, 2008). This proves the importance of physical activity and its effect on neuromuscular function. An active lifestyle will affect neuromuscular function positively at any age and may slow the age-related decline in cognitive performance associated with speed of information processing.

\section{Cardiovascular changes with ageing}

Activities of daily living and recreation depend on the heart, lungs and vasculature to adequately remove waste and transport oxygen and other nutrients to the musculature (Taylor \& Johnson, 2008). Maximum oxygen consumption $\left(\mathrm{VO}_{2} \mathrm{max}\right)$ is a measure of aerobic fitness, and describes the relationships between oxygen consumption, cardiac output, and arterialvenous oxygen difference (Taylor \& Johnson, 2008). $\mathrm{VO}_{2} \max$ declines approximately $1 \%$ each year in adult men and women (Tanaka \& Seals, 2008). This is due to the decrease in cardiac output and arterial-venous difference, and loss in muscle mass associated with ageing (Taylor \& Johnson, 2008). However, older people who are active can maintain a higher aerobic capacity than those who are sedentary (Lakatta, 2000).

The changes of the heart and blood vessels that occur with age lead to a decreased ability to transport oxygen at rest, but more so in situations where the demand for oxygen is increased. Therefore, older people may find some relatively low intensity activities physically demanding, and may not be able to be able to participate in certain activities. The age related decrease in $\mathrm{VO}_{2} \mathrm{max}$ and cardiac efficiency leads to increased fatigue (Lakatta, 2000), which may be a risk factor for falls. 
The benefits of an active lifestyle on cardiovascular health are well acknowledged. Conversely, physical inactivity has been related to the disease process leading to a number of chronic diseases including cardiovascular disease, of which age is an independent risk-factor (Taylor \& Johnson, 2008). A decrease in either aerobic or anaerobic fitness has been linked to losses of mobility and independence in older adults, as well as increased health care utilisation (Taylor \& Johnson, 2008). Training and maintaining the aerobic system enhances the ability to perform activities of daily living and maintaining the anaerobic system can reverse sarcopenia, a condition linked to an increase risk of falls (Moreland, Richardson, Goldsmith, \& Clase, 2004). Therefore, sedentary older adults may be at greater risk of falls than those who are more active.

\section{Biomechanics of gait and falls}

The likelihood of falling after a trip or stumble has been found to be related to selected individual gait characteristics, and most older adults who fall due to a trip display a distinct, specific gait pattern (Pavol, Owings, Foley, \& Grabiner, 1999). Fast walking speed, short step time and longer step length during normal walking are associated with an increased risk of falling following a trip in older adults. This type of gait is employed when hurrying while walking and increases the likelihood that an older adult will fall if they trip, due to the increase in forward momentum of the body and decrease in the time available to respond and recover from the trip (Pavol et al., 1999). This is consistent with the research which states that tripping is the most common cause of a fall and is often attributed to hurrying (W. P. Berg et al., 1997). Besides specific gait characteristics of some individuals at risk of falls, the general age-related changes to gait contradict the above, as they include reduced speed, stride length and increased double support time, which have not only been suggested to enhance stability, but also may increase the probability of falling after a trip (Pijnappels, Van der Burg et al., 2008). 
During a trip, the physical limitation posed by the obstacle, forces forward rotation of the body, which is further enhanced by gravity (Pijnappels, Reeves et al., 2008). In order to recover from the trip and prevent a fall, the individual must stop the forward motion through appropriate muscle actions. The tripping reaction consists of two phases; the positioning phase, which occurs from impact with the obstacle until placement of the recovery foot (foot landing in front) and the recovery phase, which reflects the placement of the recovery foot. When the recovery foot is placed anterior to (in front of) the body's centre of mass, the recovery limb is able to generate a moment of force which counteracts the body's forward rotation (Grabiner, Koh, Lundin, \& Jahnigen, 1993). However, the support limb is also crucial in balance recovery through generation of appropriate joint moments. An effective push-off force by the support limb provides time and clearance for proper positioning of the recovery limb. This requires a fast reduction of force in the hip flexors and knee extensors and an increase in force of the hamstring muscles. The more angular momentum is reduced by the support limb, the less its effect on the recovery limb. The greater the time and clearance provided by the support limb to swing the recovery limb forward, the better the positioning of the recovery limb and the better the ability to counter the remaining angular momentum. Pijnappels et al. (2005) found that older adults who fell after being tripped showed insufficient reduction of angular momentum during push-off and incorrect placement of the recovery limb. The most important aspect to recovery success was the ability to reduce angular momentum by a strong push-off of the support limb. Due to the decrease in strength and coordination associated with ageing, some older adults may be unable to meet the requirements for balance recovery (Pijnappels, Reeves et al., 2008).

Pijnappels et al. (2008) conducted further studies on the prevention of falls after tripping. Their studies involved tripping up individuals at different stages of the gait cycle, while attached to a safety harness for protection in the event of a fall (Pijnappels et al., 2005). In this way it could be seen which individuals were able to recover their balance or fall as a result of the trip. 
Additionally, strength measures were assessed, with an emphasis on lower extremity strength. It was found that maximum isometric push-off force in a leg press machine was the best measure to identify fallers, with $86 \%$ sensitivity, and 90\% specificity (Pijnappels, Van der Burg et al., 2008). Jump height and hand grip strength were correlated to leg press force, and may be used to classify fallers, but with lower specificity.

In a study which compared young to older subjects' responses to a trip, the kinematics and ground reaction forces of the support limb during push-off were measured (Pijnappels et al., 2005). The younger subjects did not fall, but the older subjects who did fall showed insufficient reduction of the angular momentum during push-off and incorrect placement of the recovery limb. This was due to a slower rate of change in momentum in all support limb joints and a lower peak angle momentum. Therefore, the contribution of the support limb to prevent falls from trips in older adults is reduced and even more so with increasing age. The above studies are clinically viable, but are not easily administered and may not be appealing to some individuals. The leg press measure of strength may not adequately incorporate balance measurements, as it is performed in a seated position. There is a possibility that a more functional measure of strength exists, that may be performed with minimal or at least transportable equipment. Lungetype tests might prove useful in this context as they mimic various kinematic and kinetic aspects of a trip and the front (support) leg is required to produce the majority of the forces required to regain balance.

\section{Fall risk assessment}

Fall-risk assessment tools have been used to predict the risk of falls in older adults. The choice of measurement tool in a clinical context should reflect the purpose for which the tool was developed. Validity of a test must be considered so that the test assesses what it is intended to measure. To examine the validity of a new test for lower-body strength, for example, one can compare scores of the test with the scores on a criterion test of lower- 
body strength (Rikli \& Jessie Jones, 2001). In research which screens high risk populations, testing protocols should be quick and easy to administer, while maintaining good sensitivity and specificity (Scott, Votova, Scanlan, \& Close, 2007). The sensitivity and specificity of a test reflect its validity, and in this case sensitivity refers to the proportion of true cases (people who have experienced falls) correctly categorised as having the condition by the test, and specificity is the proportion of true non-cases (people who have not experienced falls) correctly categorised as being Non-fallers (Hopkins, 2000). Different researchers state different criteria for determining 'high' predictive values. For example, Perrel et al. (2001) state that fall-risk assessment tools should have sensitivity measures above $80 \%$ and specificity above $75 \%$. Oliver et al. (2004) however, state that sensitivity and specificity measures of $70 \%$ adequately indicate 'high' predictive value. Criteria for the development or selection of tests for older adults in a practical clinical setting are presented in Table 2, adapted from Lord et al. (2007).

Table 2: Rationale for falls prediction test selection, adapted from Lord et al. (2007)

\begin{tabular}{|c|c|}
\hline Criteria & Explanation \\
\hline \multirow[t]{2}{*}{ 1. Short administration time } & Aids participation and avoids fatigue \\
\hline & Able to assess many aspects of balance \\
\hline \multirow[t]{2}{*}{ 2. Simple to administer } & Must be standardised and rigorous \\
\hline & Limited training needed \\
\hline \multirow[t]{3}{*}{ Feasible for older people } & Non-invasive \\
\hline & $\begin{array}{l}\text { Does not cause pain or require excessive } \\
\text { effort }\end{array}$ \\
\hline & $\begin{array}{l}\text { Challenging enough to distinguish } \\
\text { impairments }\end{array}$ \\
\hline \multirow[t]{2}{*}{ 4. Valid and reliable } & Criterion validity: accurately predict fallers \\
\hline & Good inter-rater and test-retest reliability \\
\hline 5. "Low-tech" and robust & $\begin{array}{l}\text { Successful implementation in large studies or } \\
\text { clinical practice }\end{array}$ \\
\hline \multirow[t]{3}{*}{ 6. Transportability } & Compact, lightweight \\
\hline & Enables testing in various settings \\
\hline & Aids participation, no participant travel \\
\hline \multirow[t]{2}{*}{ 7. Quantitative } & Continuously scored measurements \\
\hline & Can be analysed quantitatively \\
\hline
\end{tabular}


There is a lack of evidence to support a population-based approach to prevention and intervention strategies and the provision of cost-effective and efficient services is important. Therefore health care providers need appropriate risk assessment tools that reliably identify high risk individuals and are able to guide interventions through detection of risk factors for falls that may be corrected (Scott et al., 2007). Most of the available tools consist of a scoring or rating system which reflects the combined effect of known risk factors, in order to identify those individuals at greatest risk of experiencing a fall.

The risks associated with falls differ significantly among active independent seniors living in the community, those requiring long-term care, and those hospitalised for acute health problems. The fall risk among active independent older adults is generally related to mobility status, exposure to hazardous environments and risk-taking behaviours, for example climbing ladders (Scott et al., 2007). Assessment of fall risk, therefore usually involves the use of multi-factorial assessment tools (MAT) which cover a wide range of factors, or functional mobility assessment (FMA) which evaluate the physiology involved with postural stability, including strength, balance, gait, and reaction times. There are also likely to be several as yet unknown factors which affect fall prediction, which would enable health professionals to successfully determine tests to use in specific situations. For example, some tests may be more appropriate for active rather than sedentary, or older rather than younger populations (Boulgarides et al., 2003).

One common method of identifying individuals at risk of falls has been the use of a Falls History Questionnaire. This method requires the individual to recall any falls they may have sustained over the previous six months to a year. In a review of studies by Ganz et al. (2005) conclusions were that retrospective fall recall was not sensitive enough to use as a predictor of future falls. Individuals may forget falls, or not be willing to share information due to embarrassment (Cummings et al., 1988). The American Geriatrics Society (2001) recommended coupling a falls history assessment with a 
functional assessment tool, followed by a targeted intervention for reducing future incidence of falls.

Current tests are less accurate at predicting fall risk in active older adults than in more frail populations (Boulgarides et al., 2003). This constitutes the need for the development and testing of new assessment tools which may uncover balance deficits of higher functioning populations of older adults, by placing more challenging demands on the individual being tested. There are however, many tests available for assessment of the physical function of older individuals. Table 3 shows the most widely used fallrisk instruments and their relation to the criteria proposed by Lord et al. (2007).

The three types of assessments relevant to falls and mobility include: comprehensive medical assessments in outpatient or nursing home settings; nursing fall risk assessment completed in hospital and nursing home settings; and, functional mobility assessments conducted by physical therapists or physicians in an outpatient setting (Perell et al., 2001). The comprehensive assessment is used to evaluate and treat patients who are at high risk of falling, or who have recently fallen. This is an in-depth medical evaluation which is time consuming and often requires a team of clinicians and it does not necessarily provide an accurate fall risk index. The hospital and nursing home assessments include screening instruments such as the: Morse Fall Scale; STRATIFY; Resident Assessment Instrument; and, Fall Risk Assessment Tool (Perell et al., 2001), which identify those at risk so that further assessment and intervention can be proposed. The current review will focus on risk assessment of the community dwelling elderly, which is generally conducted through functional mobility assessment instruments (Perell et al., 2001) including measures such as the Tinetti Performance Orientated Mobility Assessment (POMA), Berg Balance Scale (BBS), Functional Reach and Dynamic Gait Index. These tests may be used by gerontologists, nurse practitioners, physical therapists, and exercise scientists. 
$\stackrel{n}{\sim}$

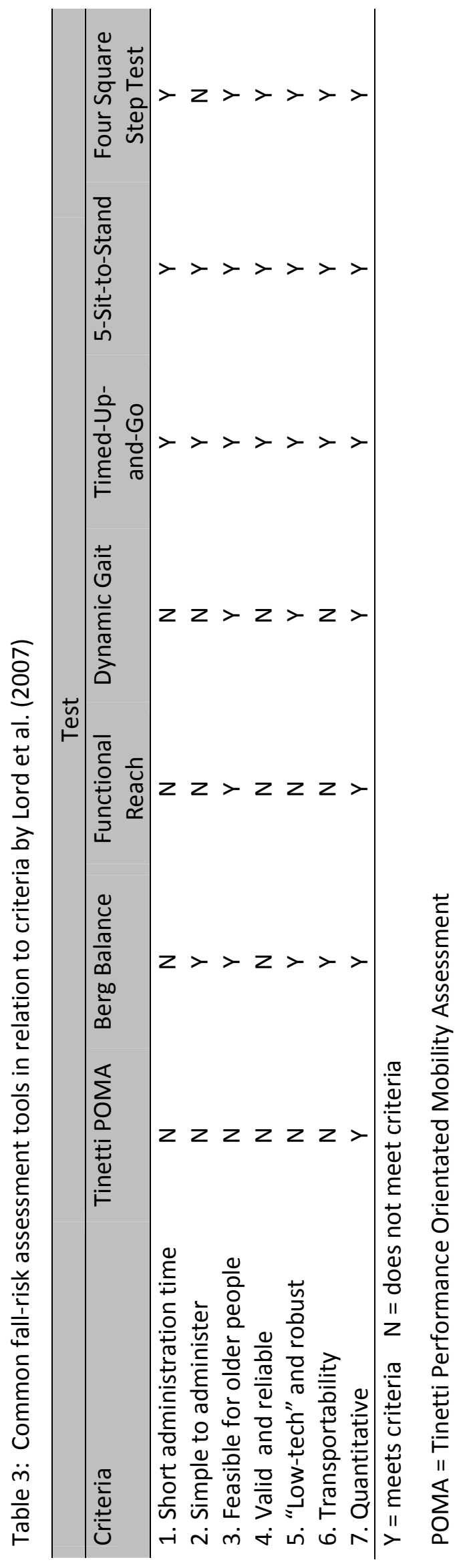




\section{Tinetti Performance Orientated Mobility Assessment}

The POMA was the earliest tool designed and prospectively evaluated to measure the effect of multiple contributing factors on fall risk (Tinetti, Williams, \& Mayewski, 1986). The assessment included three questionnaires to assess health and mobility problems, mental status and morale. The examination included a cardiac examination, lying to standing blood pressure, near and distant vision, subjective hearing, thorough neurologic and musculoskeletal examinations, and neck examinations. Balance and gait assessments were developed for the study and involved eight different balancing positions, and observations of gait with various manoeuvres (rising, sitting, turning). Endurance was also scored based on fatigue resulting from performance of the balance and gait manoeuvres and a 100 -foot walk. It was found that the balance and gait scores were the most useful in identifying recurrent fallers. Perrel et al. (2001) found the POMA scale to have an inter-rater reliability of $90 \%$ and sensitivity and specificity values of $80 \%$ and $74 \%$ respectively. The study included 79 subjects with an age range between 61 and 92 years (mean age 79 years). The study demonstrated that numerous factors contribute to fall risk, but the POMA test was unable to identify which factors contributed to increased fall risk and was laborious to administer and burdensome on the patient. This test therefore only fulfils one requirement according to criteria set by Lord et al. (2007).

\section{Berg Balance Scale}

The BBS consists of 14 tasks performed in a standard order. The tasks involve sitting to standing, and different of standing measures, such as standing with eyes closed, or standing on one foot. The scale also includes reaching and turning movements. Each task is scored on a five-point scale according to the quality of performance, or time taken to complete the task. The maximum score is 56 , and scores below 45 indicate impairment and increased risk of falling (Bogle Thorbahn \& Newton, 1996). In 66 community-living subjects with a mean age of 79 years Bogle Thorbahn et al. (1996) found the BBS test to be highly specific (96\%) in that individuals with high scores have a decreased risk of falling; but sensitivity values were low (53\%). More recently Muir et al (2008) also found this test to be inadequate for identification of the majority of people at risk of falling, due to sensitivities of $25 \%$ for any fall and 
$45 \%$ for multiple falls. The inability of the test to be a valid measure of fall-risk is most likely due to the cut-off value used in the scoring system, which is possibly easy to achieve even for those with significant impairments. The ceiling effects reported in assessment of the BBS test suggest a more challenging test is required (Rose et al., 2003).

\section{Dynamic Functional Reach test}

The Dynamic Functional Reach test is a measure of postural control which is relatively inexpensive, and clinically accessible (Duncan, Weiner, Chandler, \& Studenski, 1990). The test involves measurement of an individual's maximum standing forward reach, beyond arm length without loss of balance or stepping forward. The test results were affected by age, in that as age increased, so reach measurements decreased (Duncan et al., 1990). The study divided 128 subjects into age categories: 20 - 40 years (16); 41 - 69 years (22) and 70 - 87 years (20). The test showed high testretest reliability $(\mathrm{ICC}=0.81)$ and was associated with measurement of the centre of pressure excursion. It may therefore be useful in the assessment of instability but does not directly correlate to fall risk.

\section{Dynamic Gait Index}

The Dynamic Gait Index is a highly functional test and incorporates negotiation of obstacles, but does not assess likelihood of recovery from tripping over the obstacle. The Dynamic Gait Index was developed to evaluate and record an individual's ability to modify gait in response to changing task demands (ShumwayCook, Baldwin, \& Polissar, 1997). Task demands involve walking on a level surface, changing walking speed, performing head turns while walking, stepping over and around obstacles, pivoting during walking and stair climbing. The index rates performance from zero (poor) to three (excellent) on eight different gait tasks. During a study with 44 independent subjects aged 65 or older (mean age 76 years) the test showed sensitivity values of $59 \%$, and specificity values of $64 \%$. Therefore, it was able to correctly classify $59 \%$ of the fallers (as those who reported falls in the previous six months) and correctly identify $64 \%$ of the non-fallers. This suggests that it is not a valid measure for predicting fallers, as $50 \%$ is only as good as a random guess. 


\section{Timed Up-and-Go test}

Currently, the most frequently used assessment tools to predict for fall risk in community dwelling older adults are the Timed-Up-and-Go test (TUG) (Podsiadlo \& Richardson, 1991) and the Sit-to-Stand test (Lord, Murray, Chapman, Munro, \& Tiedemann, 2002). Various methods of administration and performance of these tests have been documented. The TUG test requires the individual to stand up from a seated position, walk three metres, turn, walk back, and sit down. The TUG has been found to be a sensitive (87\%) and specific (87\%) measure of identifying older adults at risk of falls (Shumway-Cook et al., 2000). These results were found in a study which involved fifteen older adults with no history of falls (mean age 78 years, range $65-85$ years) and fifteen older adults with a history of two or more falls in the previous 6 months (mean age 86 years, range $76-95$ years).

The TUG has been modified to the Expanded Timed Get-up-and-Go (ETGUG) test (Wall, Bell, Campbell, \& Davis, 2000), which aims to measure each of the component tasks of the original test. Each task, as well as the total test is timed with a stopwatch, in order to provide more information and isolate the areas of functional deficit. The new test reflected similar time results to the original test in the same subjects, but helped to determine which areas were most difficult, namely the turning and sitting components (Wall et al., 2000). The test was modified in an attempt to target different impairments in different individuals. The TUG and ETGUG tests meet the criteria set by Lord et al. (2007) as shown in Table 3, but are less predictive of fallers in younger and more able older adults (Shumway-Cook et al., 2000). This test is therefore better suited to frail older adults or those over 80 years old.

\section{Five Times Sit-to-Stand test}

The Fives Times Sit-to-Stand test (5-STS) requires the individual to stand up from a seated position five times (Buatois et al., 2008). In a study with 362 communitydwelling subjects aged between 74 and 98 years, this test was shown to have excellent reliability (ICC $=0.89,95 \% \mathrm{CL}=0.79,0.95)$, and poor sensitivity and specificity measures of over $50 \%$ when measured with other tests, to predict multiple fallers. It is feasible to administer in that it requires little space, and minimal equipment (Tiedemann et al., 2008). Although it meets the above criteria the 5-STS test is not a 
powerful predictor of falls, especially when used as a stand-alone measure and cannot be expected to distinguish those non-fallers at risk of future falls (Tiedemann et al., 2008).

\section{Four Square Step Test}

The Four Square Step Test (FSST) assesses the ability to take quick steps in different directions (Dite \& Temple, 2002). The test involves stepping forwards, sideways and backwards over minor obstacles in the minimum time possible. This test has been shown to be reliable across days $(I C C=0.98)$ and able to distinguish between fallers and non-fallers (Dite \& Temple, 2002). Validity was established through correlation with other existing balance tests. The FSST has been shown to have high sensitivity (89\%) and specificity (93\%) to predict multiple-fallers at a cut-off score of 13 seconds (Dite \& Temple, 2002). These results were found in a study including 81 independent subjects aged over 65 years (mean age 74 years).

\section{Summary of falls-risk assessment tools}

In review of fall-risk assessment tools, those that are used most often are more suited to the frailer older adult. A more able older adult may be at risk of falls due to balance or reaction speed deficits, but will easily manage the tests and score as 'norisk of falling'. The above tests do not take into account the prevalence of trip-type falls, or aim to place similar demands needed for recovery of this type of fall on the individual. A higher functioning individual may be classified as a Non-faller by the standard tests, but still be at risk of falls.

\section{Practical applications}

Research within the gerontology and/or health context involves identifying the health risks associated with ageing, so that they may be avoided or reduced. The aim is therefore to improve the health and well-being of older individuals, which is a growing population. Without appropriate and accurate assessment tools health professionals would not be able to identify specific impairments suffered by different individuals, and therefore would not be able to prescribe effective strategies to rectify the 
impairments (Greenwood, 1999). Without measurement tools, the outcomes and success or failure of interventions would be unknown. In the case of older adults, it is imperative to identify those at risk of falls, so that specific prevention programmes can be prescribed. Therefore, the practical application of assessment tools is crucial.

The current fall risk assessment tools are less able to predict higher functioning older adults at risk of falling. Because of the high incidence and adverse effects of falls in older adults, it is important to be able to identify those at risk. If we are able to distinguish those at risk of falls, we may be able to advise specific strength and balance training to reduce this risk. New, more demanding tests are needed to be able to predict falls. A lunge-type movement is similar to the action required to recover from a trip. The assessment therefore, of an older adult's ability to lunge forward and return may relate to their risk of falling after tripping. An assessment tool such as a lunge, may also serve as a functional training exercise to improve strength and balance, and thus reduce the risk of falls in older adults.

\section{Conclusions}

The literature has described falls in many older adults to be a common occurrence, which deserves attention due the negative consequences. Falls can lead to physical injuries, which affect the individual's quality of life and pose an economic burden. The psychological consequence is fear of falling, which leads to social isolation, reduced activity levels, subsequent muscular atrophy and further increased risk of falling. There is a need for research to distinguish between those at risk of falls among higher functioning older adults of various ages. The most frequently reported reason for a fall has been the inability to recover balance after tripping over an obstacle. Therefore, it may be appropriate that a new assessment tool is developed which demands similar movements required for recovery from a trip. Specific exercises may then be prescribed to improve the strength and balance of these individuals so they are able to avoid a fall in the event of a trip. 


\section{CHAPTER 3: RELIABILITY STUDY}

\section{Introduction}

Falls in older adults have harmful consequences including morbidity, mortality and loss of independence (Lord et al., 2007). Approximately one third of communitydwelling older adults fall at least once per year (Kannus et al., 1999). The adverse effects of falls include serious injury, functional decline, fear of falling and even death (Lord et al., 2007). Because of the high cost of falls to the individual and society much work has been done in an attempt to reduce and prevent fall incidence in older adults. There have been many interventions designed for fall prevention, but the first step for most of these programmes is falls risk assessment, which aims to identify those at greatest risk (Perell et al., 2001).

In clinical testing it is important for assessment tools to be as precise as possible, so that practical inferences can be made from test results. Two of the most essential aspects of precision are validity and reliability. The following chapter will consider the reliability of the Multiple-Lunge test with the validity study following thereafter. Reliability refers to the reproducibility of a measurement (Hopkins, 2000). A test which is not reliable means that the measurement will not be accurate. Also, poor reliability means that changes in a measurement cannot be tracked over time either in clinical studies or intervention programs. Test-retest reliability is the most common form of reliability and is examined in this study. It refers to the reproducibility of a measurement when the same subjects are tested twice or more on different occasions.

The test-retest reliability of numerous measures that have been used to predict falls in older adults has been evaluated. The validity of these tests is variable, as some may allow for easily achievable high scores, especially for the more able older adult (Rose et al., 2003). The Timed-Up-and-Go (TUG) test is a common test used to assess functional ability in community-dwelling older adults. Rockwood and colleagues (2000) found the test-retest reliability of the TUG test to be poor (ICC $=0.56)$. This may have been due to subjective scoring on the part of the interviewer, or reluctance to allow unsteady subjects to attempt the test for fear of falls. The same study found the TUG to only have $29 \%$ feasibility, a term which relates to both the ability to use an 
instrument and its appropriateness to its intended task and population (Rockwood et al., 2000). Another widely used test is the Five Times Sit-to-Stand (5-STS) test. Tiedemann et al. (2008) have shown the 5-STS test to have excellent test-retest reliability (ICC $=0.89,95 \% \mathrm{CL}=0.79,0.95)$; but it was only able to predict subjects who had suffered multiple falls with sensitivities and specificities between $50 \%$ and $60 \%$. In a dedicated reliability study, Schaubert et al. (2005b) confirmed the high test-retest reliability of the 5-STS (ICC $=0.82,95 \% \mathrm{CL}=0.68,0.92)$. However, the authors also reported a significant change in the measurement across three testing sessions $(F=$ $6.889, p=0.003$ ) and a technical error ranging from 1.7 to 2.8 seconds, suggesting a deficiency in the tests reliability.

A more challenging test, the Four Square Step Test (FSST) has been proposed as a test suited for higher functioning older adults, and those with less pronounced balance deficits (Dite \& Temple, 2002). The FSST measures an individual's ability to rapidly complete a stepping sequence over minor obstacles in forward, backwards and sideways directions. In a study similar to the present study the FSST was found to have excellent test-retest reliability $(I C C=0.98)$ and good predictive properties (sensitivity = $85 \%$; specificity $=88 \%)$. However, healthy older adults were compared to frail older adults, which would have amplified the validity results. Since its development the FSST has not been further validated, except by the same author in a study with participants that had unilateral transtibial amputations (Dite, Connor, \& Curtis, 2007), in another study involving participants with vestibular disorders (Whitney, Marchetti, Morris, \& Sparto, 2004) and lastly in a study with stroke rehabilitation patients (Blennerhassett \& Jayalath, 2008). Its use with healthy older adults may require further investigation.

Lord et al. (2007) established several criteria for fall risk assessment tools for older adults, as discussed earlier. These criteria included ease of administration, feasibility for older adults, transportability and most importantly, validity and reliability. In an attempt to meet these criteria a new falls risk assessment tool (the Multiple-Lunge test) was developed. The purpose of this study was to determine the reliability of the Multiple-Lunge test for community-dwelling older adults. The test was designed to be more challenging than the commonly used assessment tools, and therefore less likely to have ceiling effects in higher functioning older adults. A test of this nature may be able to detect subtle deficits in abilities of reaction time, strength and/or balance and thus better identify those at risk of becoming a faller. 


\section{Methods}

\section{Experimental design}

An observational design was used to measure the reproducibility of the values of the Multiple-Lunge test in the same subjects over a number of trials performed across two separate testing occasions. Each participant was allowed two to three practice steps to familiarise themselves with the movement and to limit learning effects. Two recorded trials were performed on the first testing day which constituted with-in day reliability. Seven days later an additional two trials (trial three and four) were performed to determine between-day reliability

\section{Participants}

This study formed part of the larger research project explained in the following chapter. The participants were recruited for the study through several organisations. Various retirement villages in the Auckland region were approached and advertising took place at the villages by way of newsletters, posters and/or presentations by the researcher. A number of community groups, such as the New Zealand 60s Up Movement and Returned Services Associations were also visited with the details of the study presented by the researcher, and volunteers requested. To be eligible for the study, individuals had to be 65 years or older, independently living in the community, with normal vision or vision corrected by eyewear. Individuals who had any selfreported neurological, musculoskeletal, sensory or cognitive impairments that would affect strength and balance, particularly of the lower extremity, were excluded from the study. Normal cognition was determined by the participants' ability to complete all forms and questionnaires with minimal or no assistance. For the reliability study several participants were asked to return a week after their first testing session to be re-tested. All the participants read, understood and signed an informed consent form. The study was approved by Auckland University of Technology Ethics Committee (AUTEC) in June 2009. Participant characteristics are presented in Table 5. Fall status of the participants is graphed in Figure 2. 
Table 5: Participant characteristics of reliability study subjects $(n=14)$

\begin{tabular}{lcccc}
\hline & Age $(\mathrm{yr})$ & Height $(\mathrm{m})$ & Mass $(\mathrm{kg})$ & Fall history (falls) \\
\hline Mean \pm SD & $79 \pm 6$ & $1.57 \pm 0.04$ & $69.4 \pm 10$ & $0.64 \pm 0.93$ \\
Range & $69-89$ & $1.51-1.65$ & $56.7-95.1$ & $0-3$ \\
\hline
\end{tabular}

Fall history $=$ number of falls reported within the last year

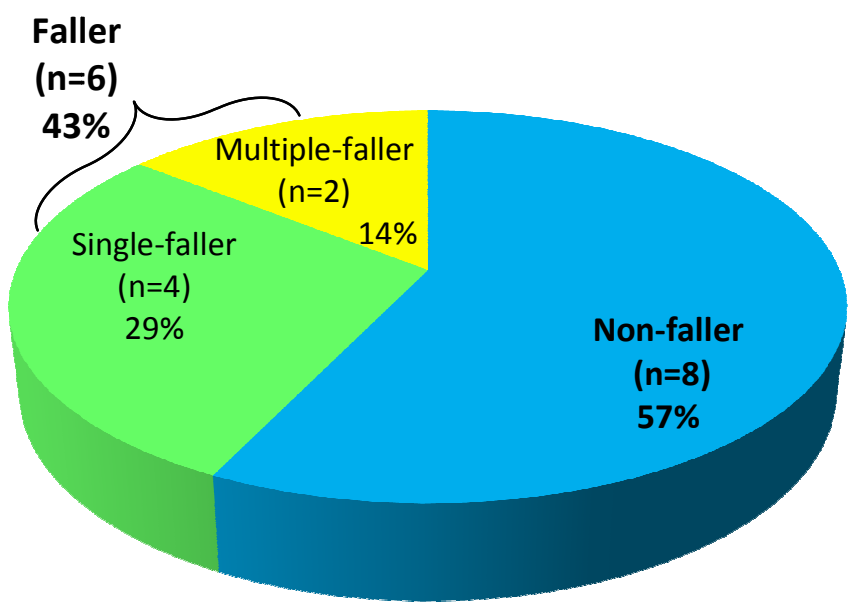

Figure 2: Fall status - reliability study

Fourteen individuals (mean age $79.14 \pm 6.64$ years) were available for the second testing session. The Falls History Questionnaire was administered to determine fallers from non-fallers. The questions included were those recommended by Lord et al. (2007) to establish a detailed history of the events surrounding a fall. A fall was defined as "an event resulting in an individual unintentionally coming to rest on the floor, or other lower level, not as the result of a major intrinsic event or overwhelming hazard" (Tinetti et al., 1988, p. 1702). This was a retrospective analysis, which surveyed individuals who had suffered one or more falls in the past 12 months. Participants who had experienced at least one fall in the previous 12 months were classified as Fallers. Multiple-fallers were those individuals who had suffered two or more falls in the previous 12 months.

The sample composed $43 \%(n=6)$ Fallers and $57 \%(n=8)$ Non-fallers. Of the six Fallers, two (14\%) were Multiple-fallers (more than one fall in the previous year). The 
proportion of Fallers in the sample was similar to the proportion generally reported in the literature for this age group (Campbell et al., 1990).

\section{Procedures}

Once the two questionnaires (PARQ and Falls History) were completed, the participants were given a demonstration and explanation of the Multiple-Lunge test. The goal was to step forward with the dominant leg to a pre-determined step length and return, for five repetitions, so that there was minimal contact time of the swing foot on each step. To enhance accuracy and due to varying body proportions, leg length was first measured from the midpoint of the anterior superior iliac spine (ASIS) of the pelvis to the midpoint of the lateral malleolus of the ankle. The required step length was calculated as $60 \%$ of leg length and marked with tape on the floor. The instructions were to start with the toes behind the first line and step forward so that the heel of the stepping foot landed passed the second line. Either leg could be chosen as the step leg. After the step foot landed the participants were to step back with that leg to the start line. They were told to aim to do the lunge step in one movement, without holding onto the tester or wall for support unless imperative to avoid a fall. A spotter was standing nearby to assist participants if they lost their balance. A stopwatch was used to determine the time taken from the "go" command to return to starting position after five repetitions. The participants performed a practice trial of between two to three steps to familiarise themselves with the movement. This was followed by two timed trials, with one minute rest in-between trials. The rest time was administered to reduce the confounding effects of fatigue. The score was recorded as the number of steps done correctly out of five steps. A step was classified as incorrect if the individual had any assistance, which may have been from the tester, walking aid, or by holding onto a wall. If the participant was unable to cross the mark on the floor with the heel of the stepping foot or had to take two steps to return to the start line the step was classified as incorrect. The total time to complete all five repetitions was also recorded. The assessors were blinded to fall status of the participants. 


\section{Statistical Analysis}

Intraclass correlation coefficients (ICCS) were used to evaluate test-retest reliability of the Multiple-Lunge test. Analysis of all trials was done using the using the Reliability spreadsheet developed by Hopkins (2000). Trial one and two were performed on the first testing day and trial three and four were performed seven days later, so represented test two. Leg length as well as subsequent step length results were analysed for change in mean between test days, in order to establish the accuracy of the procedures. Results for steps and time were analysed for change in mean between all trials. Unbiased typical error and ICCs were calculated, with $90 \%$ confidence limits. The ICC values were calculated from the formula ICC $=\left(S D^{2}-S d^{2}\right) / S D^{2}$. where $S D$ was the between-subject standard deviation and sd was the within-subject standard deviation (the standard error of measurement). ICC categories were based on standards recommended by Fliess (1986) where ICC values of 0.4 or below represent poor reliability, 0.5 to 0.6 represent moderate reliability, and values 0.75 and above represent good to excellent reliability.

\section{Results}

The results for leg length are presented in Table 6. The change in the mean leg length between test one and test two was $-1.43 \mathrm{~cm}$, however once the step distance was calculated the change in the mean was $-0.86 \mathrm{~cm}$.

Table 6: Leg length results for test 1 and test 2

\begin{tabular}{|c|c|c|c|c|}
\hline & \multicolumn{2}{|c|}{ Leg length (cm) } & \multicolumn{2}{|c|}{$60 \%$ of leg length $(\mathrm{cm})$} \\
\hline & Test 1 & Test 2 & Test 1 & Test 2 \\
\hline Mean & 88.5 & 87.1 & 53.1 & 52.2 \\
\hline SD & 3.1 & 2.8 & 1.9 & 1.7 \\
\hline $\begin{array}{l}\text { Change in mean } \\
(\mathrm{cm})\end{array}$ & \multicolumn{2}{|c|}{$-1.43(-2.37$ to -0.49$)$} & \multicolumn{2}{|c|}{$-0.86(-1.42$ to -0.29$)$} \\
\hline
\end{tabular}

The step accuracy results are presented in Table 7 and the measures of reliability displayed in Table 8 . The mean number of steps completed correctly across all trials was $3.4( \pm 2.1)$ steps. The change in the mean ( -0.43 steps) between trial two and one was slightly more than between trial three and two (-0.36 steps) and slightly less 
than between trial four and three ( 0.50 steps). The unbiased typical error was 1.05 steps between trial two and one, and trial four and three, with a minor increase between trial three and two (1.15 steps). Within-day ICC values were 0.81 and 0.79 and the between-day value was 0.77 . The recorded ICC values all classify as good (0.81, $0.77,0.79)$, as well as being similar across comparisons of trial two to one, three to two and four to three.

Table 7: Means and standard deviations for number of correct steps (out of five steps)

\begin{tabular}{|c|c|c|c|c|c|}
\hline & \multicolumn{2}{|c|}{ Steps test 1 (correct steps) } & \multicolumn{2}{|c|}{ Steps test 2 (correct steps) } & \multirow[t]{2}{*}{ Mean } \\
\hline & Trial 1 & Trial 2 & Trial 3 & Trial 4 & \\
\hline Mean & 3.8 & 3.4 & 3.0 & 3.5 & 3.4 \\
\hline SD & 2.1 & 2.3 & 2.2 & 2.0 & 2.1 \\
\hline
\end{tabular}

Table 8: Reliability for number of correct steps (out of five steps)

\begin{tabular}{lccc} 
& $\begin{array}{c}\text { Trial } 2-1 \\
\text { Within-day }\end{array}$ & $\begin{array}{c}\text { Trial 3 }-2 \\
\text { Between-day }\end{array}$ & $\begin{array}{c}\text { Trial 4 - 3 } \\
\text { Within-day }\end{array}$ \\
\hline Change in mean (steps) & $-0.43(-1.12$ to & $-0.36(-1.11$ to & $0.50(-0.19$ to 1.19) \\
& $0.26)$ & $0.40)$ & \\
Unbiased typical error & $1.05(0.80-1.56)$ & $1.15(0.88-1.71)$ & $1.05(0.80-1.56)$ \\
$\begin{array}{l}\text { (steps) } \\
\text { Intraclass correlation }\end{array}$ & $0.81(0.57-0.92)$ & $0.77(0.50-0.91)$ & $0.79(0.54-0.91)$ \\
\hline All values are mean $(90 \% \mathrm{CL})$ & &
\end{tabular}

The time scores also were used to calculate the reproducibility of the MultipleLunge test. The means and standard deviation results for total time and reliability measures for total time are summarised in Tables 9 and 10.

Table 9: Means and standard deviations for total Multiple-Lunge test time

\begin{tabular}{lccccc}
\hline & \multicolumn{2}{c}{ Time Test 1 $(\mathrm{sec})$} & \multicolumn{2}{c}{ Time Test 2 $(\mathrm{sec})$} & Mean $(\mathrm{sec})$ \\
& Trial 1 & Trial 2 & Trial 3 & Trial 4 & \\
\hline Mean & 14.8 & 14.1 & 13.4 & 12.5 & 13.7 \\
SD & 3.0 & 2.7 & 3.3 & 2.9 & 3.0 \\
\hline
\end{tabular}


Table 10: Reliability of total time to complete the Multiple-Lunge test

\begin{tabular}{lccc}
\hline & $\begin{array}{c}\text { Trial } 2-1 \\
\text { Within-day }\end{array}$ & $\begin{array}{c}\text { Trial } 3-2 \\
\text { Between-day }\end{array}$ & $\begin{array}{c}\text { Trial } 4-3 \\
\text { Within-day }\end{array}$ \\
\hline Change in mean (sec) & $-0.69(-1.42$ to 0.03$)$ & $-0.73(-1.60$ to 0.14$)$ & $-0.93(-1.77$ to - \\
& & & $0.08)$ \\
Unbiased typical error & $1.10(0.84-1.64)$ & $1.32(1.01-1.97)$ & $1.29(0.98-1.92)$ \\
$\begin{array}{l}\text { (sec) } \\
\text { Intraclass correlation }\end{array}$ & $0.88(0.71-0.95)$ & $0.84(0.64-0.94)$ & $0.86(0.67-0.94)$ \\
\hline
\end{tabular}

All values are mean $(90 \% \mathrm{CL})$

The mean time to complete the test across all trials was 13.7 seconds. A gradual decrease in mean time scores from $14.8( \pm 3.0)$ seconds to $12.5( \pm 2.9)$ seconds was evident from trial one through to trial four. Typical error was highest between trial three and two ( 1.32 seconds) and lowest between trial two and one (1.10 seconds). The within-day ICC values were 0.88 and 0.86 and the between-day value was 0.84 . Good ICC values were apparent across all comparisons $(0.88,0.84,0.86)$. Again, ICC values were similar across all comparisons.

\section{Discussion}

This study assessed the test-retest reliability of the Multiple-Lunge test across four trials with the same subjects; on the same day and across days. The relatively small sample size was due to time constraints and large recruitment efforts put into the validity section of the study. This is consistent with the research of reliability studies in which sample numbers can be as low as ten subjects (Schaubert \& Bohannon, 2005a). The required step length of the test was $60 \%$ of leg length measured from the ASIS to the lateral maleolus of the ankle. It has been found that older individuals are able to take a maximal step of $58 \%$ of their body height (Schulz, Ashton-Miller, \& Alexander, 2007). During pilot testing this step distance was deemed to be too difficult to achieve. Also, an individual does not take a maximal step in the event of a trip but rather recovery of a trip relies on the association between step length and step time (HsiaoWecksler \& Robinovitch, 2007). Leg length is generally $60 \%$ of body height. Due to differing body proportions leg length was chosen as the measure as opposed to body height. Pilot testing established $60 \%$ of leg length to be a feasible measure for the required step distance. The two test variables used to analyse reliability were the 
number of steps (out of five) performed correctly by participants, and the total time taken to complete the test. The ICC values for steps (within-day =0.8; between-day = 0.77 ) and time (within-day $=0.87$; between-day $=0.84$ ) indicated good reliability across trials.

The analysis of the step results for reliability found only small differences between trials, the greatest change in the mean between trials being 0.50 steps. The results across all trials were all within one step of each other ( 3 steps to 3.8 steps). The ICC values $(0.81,0.77,0.79)$ suggest a relatively strong correlation between trials and are classified as good according to standards by Fleiss (1986). Also, the ICC values were similar across comparisons of trial two to one, three to two and four to three. The $90 \%$ confidence limits were between 0.50 and 0.90 , which means that the true sample could lie anywhere within that range. This relatively broad confidence limit reflects the relatively small sample size $(n=14)$ used in the present study. In order to tighten these confidence limits, a larger sample size would be required. For example, a study with 31 participants reported a high test-retest reliability $(I C C=0.96)$ of the Fullerton Advance Balance Scale (FAB) with confidence limits ranging from 0.52 to 0.82 ; slightly closer than those of the present study (Rose et al., 2003).

Tests that have high reliability may not be good predictor measures in terms of their validity. Tiedemann et al. (2008) declared the 5-STS test to have excellent testretest reliability $(\mathrm{ICC}=0.89,95 \% \mathrm{CL}=0.79,0.95)$; but it was only able to predict subjects who had suffered multiple falls with sensitivities and specificities between $50 \%$ and $60 \%$. In a different study the high test-retest reliability of the 5-STS was confirmed $(\mathrm{ICC}=0.82,95 \% \mathrm{CL}=0.68,0.92)$, but a significant change in the measurement across three testing sessions ( 13.2 seconds, 12.0 seconds, 10.9 seconds) was also reported, as well as a technical error ranging from 1.7 to 2.8 seconds (Schaubert \& Bohannon, 2005b). The change in the mean across testing sessions indicates a significant learning effect, which means that sufficient familiarisation is needed for the test to be used in clinical or research settings. The average typical error across trials for the present study (1.24 seconds) was lower and implies good reliability.

The high ICC values calculated for the time scores across trials indicate good reliability $(0.88,0.84,0.86)$. These results are similar to those found in the literature, as evident in the study by Rose et al. (2003) described earlier, where the FAB scale was 
found to have a higher test-retest reliability $(I C C=0.96)$ than the present study, likely due to the larger sample size $(n=31)$. The analysis of the present study's time scores revealed a gradual decrease in mean time scores from 14.8 seconds to 12.5 seconds from trial one through to trial four. This decrease may be due to a learning effect which allowed the subjects to complete the test in a shorter time after practice. A learning effect is common in tests of physical function (Rinne, Pasanen, Miilunpalo, \& Oja, 2001; Tager, Swanson, \& Satariano, 1998). It may be that a greater opportunity for practice would allow for better familiarisation and enhanced reliability (i.e. decreased change in mean). The change in mean time scores shows an increase in the variation of scores from trial one to four. The change in the mean is greatest between trial four and three $(-0.93)$, and less between trial three and two $(-0.73)$ and least between trial two and one $(-0.69)$. Because the trend in the data is to decrease gradually, it may be that with further testing a plateau in time scores would have been reached.

The changes in mean results were higher for time than for steps, indicating a greater variability among the time scores compared to step scores. The step results were more accurate in terms of subjects' ability because each step was taken into account, whereas time was recorded over the entire test. Therefore, an individual may not have performed the entire test correctly but achieved a quicker time than someone who did (for example, the heel of the stepping foot crossed the mark with each step). The typical error for time was also higher than for steps, although ICC values for both suggest good correlations. The scoring of the number of steps successfully achieved by the participant may be a more reliable method of administering this test.

Further limitations in the methods that may have affected the reliability of the test include the measurement of leg length which was particularly difficult in overweight individuals. Leg lengths may have been inaccurate due to the tester's incorrect location of the ASIS, which could have resulted from excess fat around the area, a highly sensitive subject, or bulky undergarments. This difficulty is represented in the change in mean $(-1.43 \mathrm{~cm})$ for leg length between test one and test two. However, once sixty percent of leg length was calculated to determine step distance, the change in the mean was reduced to $-0.86 \mathrm{~cm}$. This represents a probable $1-4 \mathrm{~cm}$ difference in actual step length which would appear marginal in terms of the mechanics of the test. It may be that measurement of leg length using the greater trochanter as a marker instead of the ASIS is easier to palpate and thus more reliable. 
This suggested modification may result in even higher reliability results, due to more accurate measurement of leg length.

In order for a clinical test to be useful it needs to be both reliable and valid. The Multiple-Lunge test has been found to be a relatively reliable measure across trials, for variables of steps performed correctly and total time. It may be that the number of steps performed correctly is a more accurate measure of scoring this test, as total time to complete the test does not take into account any incorrect steps. However, such a method would mean that response time is not considered, which is crucial to falls prevention, especially in the event of a trip. The test may be more effective if the split time of each step were recorded along with the total time, as well as the number of steps performed correctly. The validity of the Multiple-Lunge test will be examined in the following chapter. 


\section{CHAPTER 4: VALIDITY STUDY}

\section{Introduction}

The population of older adults is increasing so an understanding of the issues associated with ageing is essential (Statistics New Zealand, 2009). One of the most prevalent and often injurious consequences related to ageing is falls. The incidence of falls in people 65 years and older is one fall per year in approximately $30 \%$ of the population (Campbell et al., 1990), with up to $30 \%$ of falls leading to serious injuries which hinder individuals' ability to function independently (Hausdorff et al., 2001). Older adult fallers report tripping over an obstacle as the most common type of fall (W. P. Berg et al., 1997).

Due to the many risk factors for falls in community-dwelling older adults a range of clinical tests have been designed to identify older adults who are at a higher risk of falls, so that fall prevention programmes can be implemented. The Berg Balance Scale (BBS), which measures performance on fourteen functional tasks, is the most widely used clinical assessment of balance in older adults (K. O. Berg, Wooddauphinee, \& Williams, 1992). The reliability and validity of the BBS has been well documented by various researchers (Bogle Thorbahn \& Newton, 1996; Newton, 1997; Shumway-Cook et al., 1997). However the BBS is limited when assessing older adults who may be at risk of falls, but are also reasonably high functioning. Ceiling effects have been reported when the BBS has been administered to more active community-dwelling older adults (Boulgarides et al., 2003; Muir et al., 2008). Current tests may lack the ability to detect subtle changes in balance abilities that may be occurring in higher functioning older adults (Hernandez \& Rose, 2007). A more challenging test is therefore needed for assessment of these individuals. In order for this test to be practical, it has to be quick and easy to conduct, require minimal equipment and most importantly, be valid and reliable.

The Timed-Up-and-Go (TUG) test is another tool often used to assess functional ability in community-dwelling older adults. Shumway-Cook et al. (2000) found the TUG to be a sensitive $(87 \%)$ and specific $(87 \%)$ measure for identifying those at risk of falls. However, the sample size $(n=30)$ was relatively small and the mean age of participants was 78 years in the Non-faller group, and 86 years in the Faller group, 
suggesting these may have been fairly frail individuals. In a much larger study ( $n=$ 183), Nordan et al. (2008) reported much lower sensitivity (62\%) and specificity (62\%) values of the TUG. Furthermore, this study was conducted with frail older adults living in residential care facilities and results cannot be inferred to functionally independent individuals.

The Five Time Sit-to-stand (5-STS) test is commonly used to assess independent older adults. A study by Whitney et al. (2005) found that the 5-STS test was able to correctly identify $65 \%$ of the participants with balance dysfunction, but did not find any difference in the results across age ranges. The authors concluded that the test may have been too easy for the sample of relatively healthy older adults.

It would therefore appear that while commonly used tests such as the BBS, TUG and 5-STS are able to predict falls in more frail older populations (Boulgarides et al., 2003), they are not successful in predicting fall risk in more active older adults. Furthermore, none of these tests targeted the ability to take a step, a response required to prevent a fall on tripping. The trip response is important due to the high prevalence of these types of falls. The movements required for trip recovery resemble a lunge type movement, with a large step to counter momentum in the forward direction and strong forces from the support leg to maintain balance. An assessment tool which demands similar movements required for recovery from a trip may provide useful information. Therefore, the development and validation of a new, more challenging assessment tool for the increasingly active ageing population is justified. The purpose of the following study was to determine the validity of the Multiple-Lunge test to distinguish between older (>65 years) Fallers and Non-fallers.

\section{Methods}

\section{Experimental design}

A cross-sectional sectional design was used to examine the extent to which the Multiple-Lunge test could accurately predict faller status in a group of independent older adults. Fall history was attained by retrospective self-report by participants and constituted the criterion variable. The participants were categorised as Non-fallers (no falls) or Fallers (one or more falls) based on their report of the falls they experienced in 
the previous 12 months. Two variables from the Multiple-Lunge test were investigated as the predictor variables:

- The number of steps done correctly

- The time taken to complete the test

\section{Participants}

Participants were recruited for the study through several organisations. Various retirement villages in the Auckland region were approached, and advertising was done at the villages by way of newsletters, posters and/or presentations by the researcher. A number of community groups, such as the New Zealand 60s Up Movement and Returned Services Associations were visited at meeting times where the details of the study were presented by the researcher, and volunteers requested. To be eligible for the study individuals had to be 65 years or older, independently living in the community, with normal vision or vision corrected by eyewear. Individuals who had any self-reported neurological, musculoskeletal, sensory or cognitive impairments that would affect strength and balance, particularly of the lower extremity, were excluded from the study. The Modified Physical Activity Readiness Questionnaire (PARQ) was used to determine safety to exercise. Normative cognition was determined by the participants' ability to complete all forms and questionnaires with minimal or no assistance. One individual was excluded due to age criteria and one was excluded due to very poor eyesight caused by glaucoma. All participants signed an informed consent form. The study was approved by Auckland University of Technology Ethics Committee (AUTEC) in June 2009. Participant characteristics are outlined in Table 11.

Table 11: Subject characteristics of 130 older adults

\begin{tabular}{lccccc}
\hline & Age $(\mathrm{yr})$ & Height $(\mathrm{m})$ & Mass $(\mathrm{kg})$ & $\begin{array}{c}\text { Leg length } \\
(\mathrm{cm})\end{array}$ & $\begin{array}{c}\text { Fall History } \\
\text { (falls/year) }\end{array}$ \\
\hline $\begin{array}{l}\text { Mean } \pm \text { SD } \\
\text { Range }\end{array}$ & $77 \pm 7$ & $1.63 \pm 0.09$ & $73 \pm 14$ & $88 \pm 5$ & $0.49 \pm 0.9$ \\
\hline
\end{tabular}

Fall history $=$ number of falls reported within the last year

A total of 130 independent community-dwelling adults aged 65 years or older (mean age $77 \pm 7$ years; range $65-93$ years) met the inclusion criteria. The distribution 
of participants by sex was eighty-eight (68\%) female and forty-two (32\%) male subjects. Participant numbers with regards to fall status is outlined in Figure 3.

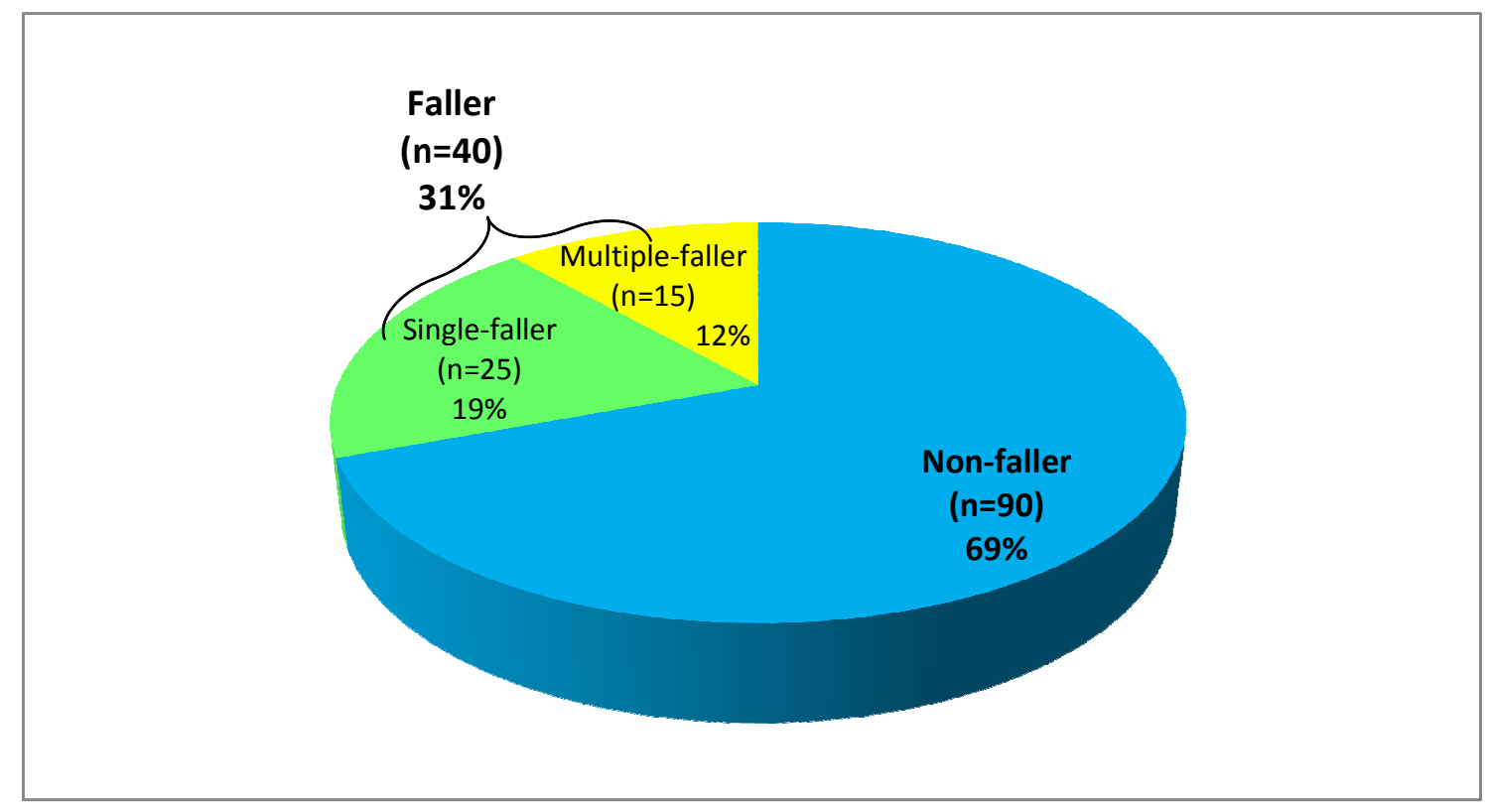

Figure 3: Fall status of 130 participants

The Falls History Questionnaire was administered to determine Fallers from Non-fallers. The questions included were those recommended by Lord et al. (2007) to establish a detailed history of the events surrounding a fall. A fall was defined as "an event resulting in an individual unintentionally coming to rest on the floor, or other lower level, not as the result of a major intrinsic event or overwhelming hazard" (Tinetti et al., 1988, p. 1702). This was a retrospective analysis, which reflected individuals who had suffered one or more falls in the past 12 months.

Forty subjects reported at least one fall in the previous 12 months and were named the Faller group. The Faller group was further divided into Single Fallers $(n=25)$ and Multiple Fallers $(n=15)$. Those classified as Fallers comprised $31 \%$ of the sample. A total of 40 participants reported 64 falls in the previous 12 months. The Multiplefallers comprised $38 \%$ of the Faller group. Of the Faller group, the Multiple-fallers included those who had fallen twice $(23 \%)$, three times $(8 \%)$ and four times (8\%). Reasons for falls were described, and are presented in Table 12. The most common cause of a fall was a trip (61\%), followed by turning (9\%) and a slip (8\%). 
Table 12: Reasons for falls as reported retrospectively by forty older adults with a history of falls

\begin{tabular}{ccccccccccc}
\hline & Trip & Turning & Slip & $\begin{array}{c}\text { Getting } \\
\text { up } \\
\text { quickly }\end{array}$ & $\begin{array}{c}\text { Walking } \\
\text { fast }\end{array}$ & Stroke & Sport & $\begin{array}{c}\text { Getting } \\
\text { into car }\end{array}$ & $\begin{array}{c}\text { Total } \\
\text { falls }\end{array}$ \\
\hline $\mathrm{n}$ & 39 & 6 & 6 & 5 & 4 & 2 & 1 & 1 & 64 \\
$\%$ & 60.9 & 9.4 & 9.4 & 7.8 & 6.3 & 3.1 & 1.6 & 1.6 & 100 \\
\hline
\end{tabular}

\section{Physical activity}

The Rapid Assessment of Physical Activity Questionnaire (RAPA) allowed the determination of the amount of different types of physical activity (light, moderate, or vigorous) the participant engaged in during a normal week. Questions relating to strength and flexibility activities were also included. The questionnaire was scored to categorise each individual's physical activity levels as either Sedentary, Under-active or Active. The RAPA has been found to have moderate to high sensitivity (81\%) and specificity (69\%) to predict activity participation in older adults (Topolski et al., 2006).

Subject physical activity categories by group are displayed in Table 13 . There was no significant between group differences in subject physical activity categories. Both the Non-faller and Faller group had a low percentage of sedentary participants (3.3\% and $2.5 \%$ respectively). The majority of subjects from all groups were scored a physical activity level of 'under-active'.

Table 13: Subject physical activity categories by group

\begin{tabular}{lccccccc}
\hline & \multicolumn{2}{c}{ Sedentary } & \multicolumn{2}{c}{ Under-active } & \multicolumn{2}{c}{ Active } & \\
& $\mathrm{n}$ & $\%$ & $\mathrm{n}$ & $\%$ & $\mathrm{n}$ & $\%$ & \\
\hline Non-faller & 3 & 3.3 & 55 & 61.1 & 32 & 35.6 & \\
Faller & 1 & 2.5 & 29 & 72.5 & 10 & 25 & \\
Total subjects & 4 & & 84 & & 42 & & 130 \\
Single-faller & 0 & 0 & 20 & 80 & 5 & 20 & \\
Multiple- & 1 & 6.7 & 9 & 60 & 5 & 33.3 & \\
faller & 1 & & 29 & & 10 & & 40 \\
\hline Total fallers & 1 & & & & & & \\
\hline
\end{tabular}

Subject participation in strength and flexibility activities by group are outlined in Table 14. There was no significant between group differences in strength and 
flexibility activity participation. The Multiple-fallers did however present with the highest percentage $(73.3 \%)$ of subjects who did not take part in either strength or flexibility activities. Approximately half $(48.9 \%)$ of the Non-faller group were participating in either strength or flexibility activities or both, on a regular basis.

Table 14: Subject participation in strength and flexibility activities by group

\begin{tabular}{|c|c|c|c|c|c|c|c|c|c|}
\hline & \multicolumn{2}{|c|}{ Strength } & \multicolumn{2}{|c|}{ Flexibility } & \multicolumn{2}{|c|}{$\begin{array}{l}\text { Strength and } \\
\text { Flexibility }\end{array}$} & \multicolumn{2}{|c|}{$\begin{array}{l}\text { No Strength } \\
\text { or Flexibility }\end{array}$} & \\
\hline & $\mathrm{n}$ & $\%$ & $\mathrm{n}$ & $\%$ & $n$ & $\%$ & $\mathrm{n}$ & $\%$ & \\
\hline Non-faller & 8 & 8.9 & 23 & 25.6 & 13 & 14.4 & 46 & 51.1 & \\
\hline Faller & 1 & 2.5 & 10 & 25 & 3 & 7.5 & 26 & 65 & \\
\hline Total subjects & 9 & & 33 & & 16 & & 72 & & 130 \\
\hline Single-faller & 1 & 4 & 8 & 32 & 1 & 4 & 15 & 60 & \\
\hline $\begin{array}{l}\text { Multiple- } \\
\text { faller }\end{array}$ & 0 & 0 & 2 & 13.3 & 2 & 13.3 & 11 & 73.3 & \\
\hline Total fallers & 1 & & 10 & & 3 & & 26 & & 40 \\
\hline
\end{tabular}

\section{Procedures}

After completing the three questionnaires (PARQ, Falls History and RAPA), the participants were given a demonstration and explanation of the Multiple-Lunge test. The goal was to step forward with the dominant leg to a pre-determined step length and return, for five repetitions in the minimal overall time. In an attempt to reduce the potential effect of varying body proportions, leg length was first measured from the midpoint of the anterior superior iliac spine (ASIS) of the pelvis to the midpoint of the lateral malleolus of the ankle. The required step length for the Multiple-Lunge test was calculated as $60 \%$ of leg length and marked with tape on the floor. The instructions were to start with the toes behind the first line and step forward so that the heel of the stepping foot landed passed the second line. Either leg could be chosen as the step leg. After the step foot landed the participants were to step back with that leg to the start line. They were told to attempt the lunge step in one movement, without holding onto the tester or wall for support unless imperative to avoid a fall. A spotter was standing nearby to assist participants if they lost their balance. A stopwatch was used to determine the time taken from the "go" command to the return to starting position after five repetitions. The participants performed a practice trial of between two to three steps followed by two timed trials, with one 
minute rest period after the first. The score was recorded as the number of steps performed correctly out of five steps. A step was classified as incorrect if the subject had any assistance, which may have been from the tester, walking aid, or by holding onto a wall. If the participant was unable to cross the mark on the floor with the heel of the stepping foot or had to take two steps to return to the start line the step was classified as incorrect. The trial with the most correct steps was recorded as the Multiple Lunge test score. The total time to complete the test was also recorded.

\section{Statistical Analysis}

In order to establish the accuracy of the Multiple-Lunge test in distinguishing between Non-fallers and Fallers, and thus the ability to predict falls in older adults, the sensitivity and specificity of the test was calculated. Sensitivity refers to the proportion of people who are Fallers who test positive. If sensitivity is high, a negative test will rule out high fall risk. Specificity refers to the proportion of people who are not Fallers who test negative. If specificity is high, a positive test will rule in high fall risk (Davidson, 2002). Diagnostic test characteristics are defined and calculations shown in Table 15. These characteristics were determined using the truth table, adapted from Davidson (2002) displayed in Figure 4.

Table 15: Definitions and calculations of test characteristics, adapted from Davison (2002)

\begin{tabular}{|c|c|c|}
\hline Test characteristic & Definition & Calculation \\
\hline Sensitivity & $\begin{array}{l}\text { The proportion of people who have the } \\
\text { disorder who test positive }\end{array}$ & $a /(a+c)$ \\
\hline Specificity & $\begin{array}{l}\text { The proportion of people who do not } \\
\text { have the disorder who test negative }\end{array}$ & $d /(b+d)$ \\
\hline Positive Predictive & $\begin{array}{l}\text { The proportion of people who test } \\
\text { positive who have the disorder }\end{array}$ & $a /(a+b)$ \\
\hline Negative & The proportion of people who test & $d /(c+d)$ \\
\hline Predictive & negative who do not have the disorder & \\
\hline Accuracy & $\begin{array}{l}\text { The proportion of people who were } \\
\text { correctly identified as either having or not } \\
\text { having a history of falls }\end{array}$ & $(a+d) /(a+b+c+d)$ \\
\hline Prevalence & $\begin{array}{l}\text { The proportion of people in the sample } \\
\text { who were Fallers }\end{array}$ & $(a+c) /(a+b+c+d)$ \\
\hline
\end{tabular}




\begin{tabular}{|c|c|c|c|}
\hline & $\begin{array}{l}\text { Present } \\
\text { (Faller) }\end{array}$ & $\begin{array}{l}\text { Absent } \\
\text { (Non-faller) }\end{array}$ & Totals \\
\hline Positive Predictor & $\begin{array}{l}\text { True Positive } \\
\boldsymbol{a} \\
\text { Predicts Faller } \\
\text { Actual Faller }\end{array}$ & $\begin{array}{l}\text { False Positive } \\
\boldsymbol{b} \\
\text { Predicts Faller } \\
\text { Not actual Faller }\end{array}$ & $a+b$ \\
\hline Negative Predictor & $\begin{array}{l}\text { False Negative } \\
\text { c } \\
\text { Predicts Non-faller } \\
\text { Actual Faller }\end{array}$ & $\begin{array}{l}\text { True Negative } \\
\boldsymbol{d} \\
\text { Predicts Non-faller } \\
\text { Not actual Faller }\end{array}$ & $c+d$ \\
\hline Totals & $a+c$ & $b+d$ & $a+b+c+$ \\
\hline
\end{tabular}

Figure 4: A two by two, or 'truth' table to calculate predictive properties of an assessment tool, adapted from Davidson (2002).

After the initial analysis using truth tables, a more complex logistic regression analysis was performed using SPSS (version 17.0). The aim was to determine the variables that best predicted the probability of falling. The Multiple-Lunge test consists of two variables: the number of steps (out of five) a participant is able to perform successfully, and the total time taken to complete the test. The linear regression analysis was run for two variables in order to establish the predictive validity of the Multiple-Lunge test. The first variable used to calculate a predicted number of falls was the number of steps each subject could perform correctly. The second variable used was total time taken to complete the test. Finally step number and time were both used in the linear regression to calculate a predicted fall value. These variables were used to compare Fallers to Non-fallers; as well as Multiplefallers to both Non-fallers and Single-fallers. The predicted falls value was compared to the actual falls value in order to determine true negatives, false negatives, true positives and false positives; which were then used to calculate sensitivity and specificity. 
Results

Multiple-Lunge test

Initial analysis

The number of steps performed correctly by each group is presented in Figures 5 and 6.

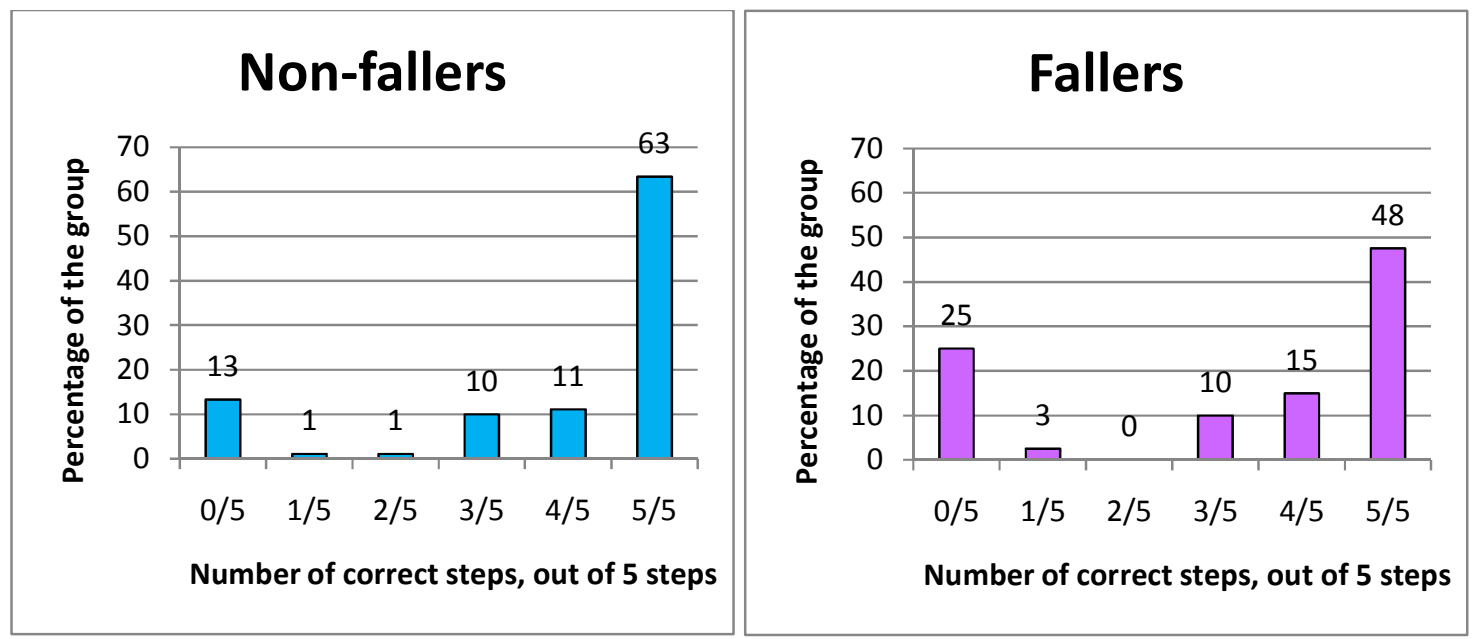

Figure 5: Percentage of Non-fallers and Fallers and the number of steps performed correctly from five steps
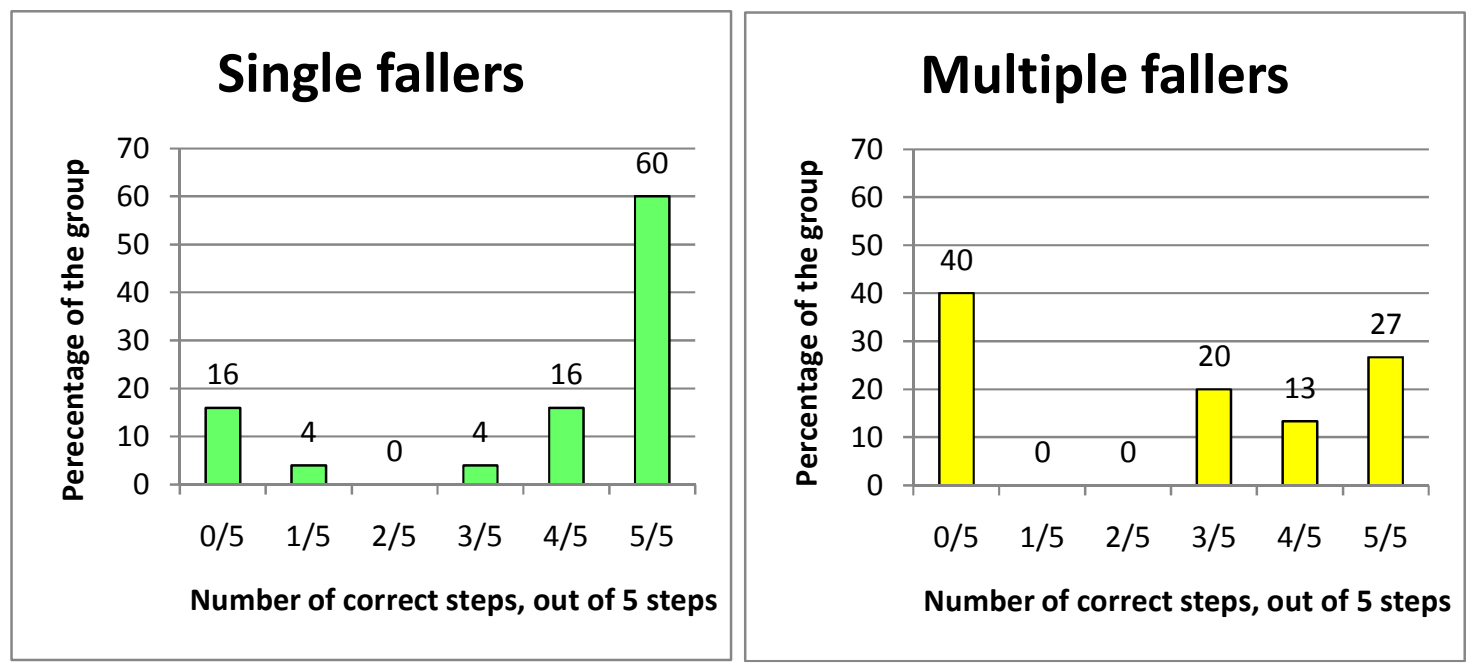
Figure 6: Percentage of Single-fallers and Multiple-fallers and the number of steps performed correctly from five steps

Five out of five steps were performed correctly by $63 \%$ of the Non-faller group, whereas only $48 \%$ of the Faller group were able to successfully complete five out of five steps. This difference is greater when the Faller group is divided into Single and Multiple-fallers. Sixty percent of the Single-fallers, compared to only $27 \%$ of the Multiple-faller group were able to correctly perform all five steps.

The ability of the test to distinguish between Non-fallers and Fallers (sensitivity and specificity, and predictive values) was determined by placing the above results in truth table format. Comparison 1 evaluated the percentage of participants with zero out of five steps correct, and involved comparisons of Fallers to Non-fallers, as well as Multiple-fallers to Non-fallers. Comparison 2 evaluated the percentage of participants with five out of five steps correct, using the same comparisons (see appendix for truth tables). The predictive properties of the Multiple-Lunge test were then calculated, and are presented in Table 16.

Table 16: Sensitivity, specificity, predictive values, accuracy and prevalence values for Multiple-Lunge test by number of correct steps

\begin{tabular}{|c|c|c|c|c|}
\hline & $\begin{array}{c}\text { Comparison 1: } \\
\text { (0/5 steps) } \\
\text { F vs. NF }\end{array}$ & $\begin{array}{c}\text { Comparison } 1: \\
\text { (0/5 steps) } \\
\text { MF vs. NF }\end{array}$ & $\begin{array}{c}\text { Comparison 2: } \\
\text { (5/5 steps) } \\
\text { F vs. NF }\end{array}$ & $\begin{array}{c}\text { Comparison 2: } \\
\text { (5/5 steps) } \\
\text { MF vs. NF }\end{array}$ \\
\hline Sensitivity & $25 \%$ & $40 \%$ & $53 \%$ & $73 \%$ \\
\hline Specificity & $87 \%$ & $87 \%$ & $63 \%$ & $63 \%$ \\
\hline $\begin{array}{l}\text { Positive Predictor } \\
\text { Negative }\end{array}$ & $65 \%$ & $75 \%$ & $59 \%$ & $67 \%$ \\
\hline Predictor & $54 \%$ & $59 \%$ & $57 \%$ & $70 \%$ \\
\hline Accuracy & $56 \%$ & $63 \%$ & $58 \%$ & $68 \%$ \\
\hline Prevalence & $50 \%$ & $50 \%$ & $50 \%$ & $50 \%$ \\
\hline Sensitivity $=a /(a+c)$ & \multicolumn{4}{|c|}{ Specificity $=d /(b+d)$} \\
\hline Positive Predictor $=$ & $a /(a+b)$ & \multicolumn{3}{|c|}{ Negative Predictor $=d /(c+d)$} \\
\hline Accuracy $=(a+d) /(a-$ & $+b+c+d)$ & \multicolumn{3}{|c|}{ Prevalence $=(a+c) /(a+b+c+d)$} \\
\hline $\begin{array}{l}\mathrm{F}=\text { Faller } \\
\mathrm{MF}=\text { Multiple-faller }\end{array}$ & & \multicolumn{3}{|c|}{$N F=$ Non-faller } \\
\hline
\end{tabular}


The highest specificity (87\%) was achieved using comparison 1, zero steps correct out of five steps. However, this comparison resulted in low specificity, $25 \%$ for Fallers vs. Non-fallers and $40 \%$ for Multiple-fallers vs. Non-fallers. Comparison 2, all steps correct, resulted in moderate sensitivity and specificity, but these values were greater (sensitivity $=73 \%$; specificity $=63 \%$ ) when Multiple-fallers and Non-fallers were compared.

The highest positive predictor variable (75\%) was for comparison 1 (Multiplefallers vs. Non-fallers), but the negative predictor (59\%) was only moderate. The highest negative predictor (70\%), with a positive predictor of $67 \%$, was for comparison 2, Multiple-fallers and Non-fallers. Accuracy of the test was higher ( $1=63 \% ; 2=68 \%$ ) in the Multiple-faller and Non-faller comparisons, for both conditions, than the Faller, Non-faller comparisons ( $1=56 \% ; 2=58 \%)$.

\section{Linear regression analysis}

The results from the linear regression analysis are presented in Table 17. None of the regression analyses resulted in high values for both sensitivity and specificity. The variables used were; (1) number of correct steps, (2) time to complete the test, and, (3) both steps and time. The comparisons used were: (1) Fallers to Non-fallers and, (2) Multiple-fallers to both the Non-faller and Single-faller groups. When comparing Fallers to Non-fallers the steps variable resulted in moderate specificity (74\%) with low sensitivity (38\%). The comparison of Multiple-fallers to Non- and Singlefallers using both steps and time variables produced very high specificity (98\%), but low sensitivity (20\%).

Table 17: Sensitivity and specificity values for different variables as determined using predicted fall values from linear regression analysis

\begin{tabular}{|c|c|c|c|c|c|c|}
\hline & $\begin{array}{c}\text { Steps } \\
\text { F vs. NF }\end{array}$ & $\begin{array}{c}\text { Steps } \\
\text { MF vs. NF } \\
\text { and SF }\end{array}$ & $\begin{array}{c}\text { Time } \\
\text { F vs. NF }\end{array}$ & $\begin{array}{c}\text { Time } \\
\text { MF vs. NF } \\
\text { and SF }\end{array}$ & $\begin{array}{c}\text { Steps } \\
\text { and Time } \\
\text { F vs. NF }\end{array}$ & $\begin{array}{l}\text { Steps and } \\
\text { Time } \\
\text { MF vs. NF } \\
\text { and SF }\end{array}$ \\
\hline Sensitivity & $38 \%$ & $0 \%$ & $30 \%$ & $20 \%$ & $98 \%$ & $20 \%$ \\
\hline Specificity & $74 \%$ & $100 \%$ & $80 \%$ & $99 \%$ & $0 \%$ & $98 \%$ \\
\hline $\mathrm{F}=$ Faller & & \multicolumn{5}{|c|}{ MF = Multiple-faller } \\
\hline
\end{tabular}


Data from the linear regression analysis with respects to the three predictors of falls is presented in Table 18. Of the three predictor variables the highest R-squared value was for both steps and time (0.169), whereas steps alone as a predictor variable resulted in an R-squared value of 0.091 . The standard error of the estimate (SEE) was lowest for time as the predictor variable (0.013) and greater for the remaining two variables (steps $=0.861 ;$ steps and time $=0.827)$.

Table 18: Linear regression predictors of falls; Fallers vs. Non-fallers

\begin{tabular}{|c|c|c|c|c|c|}
\hline \multirow[t]{2}{*}{ Predictor } & \multicolumn{3}{|c|}{ Pearson correlations } & \multirow[b]{2}{*}{$\beta$} & \multirow{2}{*}{$\begin{array}{c}\text { Linear Regression } \\
\text { SEE (falls) }\end{array}$} \\
\hline & $\mathrm{R}$ & $r^{2}$ & $P$ value & & \\
\hline Steps & 0.302 & 0.091 & $<0.001$ & -0.302 & 0.861 \\
\hline Time & 0.394 & 0.155 & $<0.001$ & 0.394 & 0.013 \\
\hline Steps and time & 0.412 & 0.169 & $<0.001$ & $\begin{array}{l}\beta_{1}=-0.137 \\
\beta_{2}=0.325\end{array}$ & 0.827 \\
\hline
\end{tabular}

$\beta_{1}=$ steps

$\beta_{2}=$ time

\section{Discussion}

The aim of the study was to determine the validity of the Multiple-Lunge test to distinguish between older Fallers and Non-fallers. The results suggest that the Multiple-Lunge test was better able to distinguish Multiple-fallers than Single-fallers, based on the number of steps (out of five) performed correctly.

There were small to moderate differences between groups in terms of Multiple- Lunge test performance. Five out of five steps were done correctly by $63 \%$ of the Non-faller group, whereas only $48 \%$ of the Faller group were able to successfully complete five out of five steps. This difference was greater when the Faller group was divided into Single and Multiple-fallers. Sixty percent of the Single-fallers, compared to only $27 \%$ of the Multiple-faller group were able to correctly perform all five steps. This very basic analysis shows a difference in the abilities of Multiple-fallers opposed to Non-fallers. It may be inferred that individuals who are unable to successfully execute five out of five steps as detailed in procedures above, are at risk of Multiple-falls. The initial analysis calculated sensitivity and specificity values for two conditions. Comparison one evaluated the percentage of participants with zero out of five steps 
correct. Comparison two evaluated the percentage of participants with five out of five steps correct. Both comparisons compared Fallers to Non-fallers, and then Multiplefallers to Non-fallers. Although specificities for both comparisons were high for comparison one $(87 \%)$, sensitivities were low (25\% for Faller versus Non-faller; and $40 \%$ for Multiple-faller versus Non-faller). Therefore, participants who are unable to complete the test correctly may be at risk of falls, but participants who are able do the test correctly cannot necessarily be classified as Non-fallers.

The comparison which resulted in the highest sensitivity (73\%) and specificity (63\%) was comparison two, Multiple-fallers versus Non-fallers. This implies that an individual who is able to do the test well (i.e. tests negative for falls) has $73 \%$ chance of not being a Multiple-faller. And, an individual who is unable to perform the test well (i.e. tests positive for falls) has $63 \%$ chance of being a Multiple-faller. The results for the comparison two analysis are therefore somewhat better than chance, but how do these results compare to the falls prediction literature for older adults?

Shumway-Cook et al. (1997) used a similar analysis to determine the predictive properties of the BBS and reported a sensitivity of $77 \%$ and specificity of $86 \%$ to classify those with history of falls (Mulitple-fallers). Although these values were higher than the present study, the sample used by Shumway-Cook et al. (1997) was small ( $n=$ 44), and comprised older adults with greater levels of functional impairment. Also, the Faller and Non-faller groups were equal in size, which is not truly representative of the proportion ( $\pm 30 \%$ ) of Fallers to Non-fallers that exist in the older adult population (W. P. Berg et al., 1997; Lord et al., 2007; Tinetti, 1994). The present study found that the number of participants in the different groups corresponds to previous studies, especially those with a similar mean age of participants. We found that $31 \%$ of participants (mean age $77 \pm 7$ years) were classified as fallers, confirming results of an early study by Tinetti et al. (1988) which monitored fall status prospectively in a group of subjects with a mean age of 78 years, and concluded that $32 \%$ fell at least once in a year.

A more recent study by Hernandez et al. (2007) evaluated the ability of the Fullerton Advanced Balance (FAB) scale to predict falls in older adults. This study was also based on retrospective self-report of falls, but those classified as Fallers had suffered two or more falls over the previous 12 months. The study determined that a cut-off score of 25 out of 40 on the FAB scale produced a sensitivity of $75 \%$ and 
specificity of $53 \%$. It was concluded that in 7 out of 10 cases that individuals who score lower than 25 on the FAB scale are at risk of falls. However, this test may not be able to predict those at risk of a single fall as these individuals were excluded from the study. The fact that the Faller group had sustained two or more falls suggests that they had increased weaknesses compared to the Single-faller sample used in the present study. Furthermore, the low specificity value (53\%) means that those individuals who were able to score above 25 on the scale may still be at risk of falls.

The results reported by Hernadez et al. (2007) above are similar to the results found in the present study, although specificity (63\%) was higher in the present study, for the prediction of Multiple-fallers. Buchner and colleagues (1993) suggested that studies of this nature should not classify individuals as Fallers if they have only suffered one fall in the previous year, but rather exclude them from the study. These individuals may not be truly representative of individuals with a physiologic predisposition to falling (Buchner et al., 1993). In the case of the present study excluding Single-fallers may have produced higher validity results, as evident from higher sensitivities achieved using the Multiple-faller group; but recruitment difficulties did not allow such a method if the required sample size was to be met. Also to be truly representative of the older adult population, the Faller group may need to include those that have only fallen once. Hernadez et al. (2007) stated that it is more important that a scale demonstrate higher sensitivity versus specificity, which has been achieved in the present study.

A number of limitations may have contributed to the moderate specificity observed in the present study. First of all, the large age range (65 - 93 years) may have increased the variability and diversity of the sample. It is well acknowledged that rates of fall incidence and the likelihood of falling increases with age (Lord et al., 1991). The physiological changes associated with ageing affect balance, reaction time and strength (Sturnieks et al., 2008), and therefore the older individuals in the sample may have achieved significantly different results to the younger individuals, regardless of fall status. Secondly, the use of a retrospective research design may have caused limitations in grouping participants based on falls history. Individuals were asked to recall the number of falls they had sustained in the previous 12 months, which requires good memory recall. The use of a prospective design in which fall incidence is 
monitored over time may have allowed a more accurate evaluation of the MultipleLunge test's predictive properties.

The three predictors of falls analysed by linear regression were number of steps done correctly, time taken to complete the test, and the combination of both steps and time. None of these three approaches resulted in high values for both sensitivity and specificity. When comparing Fallers to Non-fallers the steps variable resulted in moderate specificity (74\%) with low sensitivity (38\%). The comparison of Multiplefallers to Non- and Single-fallers using both steps and time variables produced very high specificity (98\%), but low sensitivity (20\%). The high specificity means that individuals who cannot perform all five steps of the test may be at risk of multiple falls. However due to the low sensitivity, a test result of five out of five steps completed correctly may not mean a low risk of falls.

Possible reasons for low specificity results include the limitations of age range and retrospective design discussed earlier. Also, the sample size of the Multiple-faller group was small $(n=15)$. The Multiple-fallers comprised $38 \%$ of the Faller group, which was slightly less than the $50 \%$ reported in the literature (Hanlon, Landerman, Fillenbaum, \& Studenski, 2002; Oloughlin, Robitaille, Boivin, \& Suissa, 1993). This may be due to the limitation caused by retrospective self-report which often results in under-reporting. It is possible that subjects may have forgotten falls they had sustained, or when they occurred (Cummings et al., 1988). It is also probable that subjects did not want to report falls due to embarrassment (Lord et al., 2007). A larger sample size of the Multiple-fallers may have produced better results, but recruitment difficulties did not allow this.

Furthermore, the functional ability of the participants may not have been as high as expected, if physical activity levels are any indication of ability. Physical activity levels were assessed and the majority of participants were classified as 'under-active'. A strength of the study was that there was no apparent difference between groups with regards to physical activity levels, which means that physical activity questionnaires alone may not be able to predict falls risk, and there is a need for a more functional falls risk tool. Of all subjects $67 \%$ were categorised as 'under-active'. However, the RAPA questionnaire scored individuals as 'under-active' even if they did participate in some physical activity every week, but for less than 30 minutes a day, or 5 days a week. The sample may have been slightly different to the general older adult 
population in terms of physical activity levels according to a survey by the Ministry of Health (2007), which found that $67 \%$ of women and $76 \%$ of men aged $65-74$ years were 'physically active'. These levels decreased with advanced age. The percentage of total subjects classified as 'active' in the present study was 30\%; whereas the Ministry of Health labelled $46 \%$ of women and $52 \%$ of men aged $65-74$ years in this category. However, different definitions used in the literature make these comparisons difficult and the conclusions therefore unclear. According to the Ministry of Health (2007) 'physically active' is defined as doing at least 2.5 hours of physical activity in the last week, with exercise accumulated on one or more days of the week, a definition similar to the RAPA definition for 'under-active'.

There were slight differences between groups with respect to regular participation in strength and flexibility activities. Multiple-fallers had the highest percentage $(73 \%)$ of participants who did not take part in any strength or flexibility activities. Approximately half (49\%) of the Non-faller group had participated in either strength or flexibility activities or both, on a regular basis. As strength activities have been identified as exercises which can reduce the incidence of falls in older adults (American Geriatrics Society et al., 2001; Stone, Collins, Plisk, Haff, \& Stone, 2000), falls suffered by the Multiple-faller group may be a result of a lack of participation in these activities.

The Multiple-Lunge test was found to be more predictive of falls in a group of Multiple-fallers than Single-fallers, with sensitivity of $73 \%$, and specificity of $63 \%$, using the variable of five out of five steps done correctly. This test was also found to be reliable measurement across trials with the same subjects (ICC $=0.79$ for steps; ICC $=$ 0.86 for time). Most of the literature around validation of falls risk assessment tools has used Multiple-fallers only, and has excluded those who report one fall, which confirms the results of the present study. There may be certain modifications that can be made to the test to increase its validity to predict fallers in higher functioning older adults. Development of a cut-off score may be more predictive, for example the ability/inability to correctly perform three or four out of five steps. Use of split times per step as well as step accuracy scores may improve validity, while providing more information on reaction time abilities. Assessment of the maximum number of correct lunges that can be performed within a certain time may also be useful. The high level of difficulty of such a test may eliminate the ceiling effects found in other studies, and 
show greater discrimination between fallers and non-fallers than the present study. Further modifications include use of the greater trochanter as a measurement point for leg length, which may result in even better reliability, as mentioned in the previous chapter. This test is not intended for frail older adults and should only be used with independent community-dwelling older adults due to the challenging nature of the test.

The results suggest there is potential for the Multiple-Lunge test to be used in assessment of older adults, but additional research is needed before it can be used in clinical or research practice. The good test-retest reliability results suggest it may be a useful tool in evaluating the success of intervention programmes; however research is needed to establish how to increase its validity to predict those at risk of future falls. The limitations and suggestions discussed above provide a starting point for this process. 


\section{CHAPTER 5: CONCLUSION}

The purpose of this chapter is to discuss the main results of the experimental chapters of this thesis and to show how these findings add to the literature on fall prevention assessment tools in older adults. A summary of the main findings from each of the experimental chapters is presented, as well as how these results compare and add to the literature on fall risk assessment tools. This integration will then be used to discuss practical implications for the assessment of independent older adults, followed by recommendations for future research.

\section{Summary of results}

\section{Characteristics of fall risk assessment tools}

A review of the literature revealed that numerous tools have been developed to assess the risk of falls in older adults. The reason for the development of these measures is to distinguish those at risk, so that specific intervention strategies aimed at reducing falls risk can be recommended and thus the occurrence of falls reduced. The most commonly used tests have been shown to be less able to predict falls in higher functioning older adults, compared to the more frail older adult population (Boulgarides et al., 2003; Muir et al., 2008). Furthermore, few of these tests focused on the ability to take a step, a response required to prevent a fall on tripping. The trip response is significant due to the fact that trips are the most common cause of falls, especially in community-dwelling older adults (W. P. Berg et al., 1997). Therefore, this thesis aimed to assess the reliability and validity of a new, more challenging assessment tool involving a stepping (lunge) movement for the independent higher functioning ageing population. A summary of the main findings of each of the two experiments is presented.

\section{Experiment 1: reliability study}

- Good reliability was found for the number of correct steps across four trials (ICC within-day $=0.8$; ICC between-day $=0.77)$. The change in mean scores 
were -0.43 steps, -0.36 steps and 0.50 steps between trials two and one, three and two, and four and three respectively.

- Good reliability was found for total time (ICC within-day $=0.87$; ICC betweenday $=0.84)$. The change in mean scores were -0.69 seconds, -0.73 seconds and 0.93 seconds between trials two and one, three and two, and four and three respectively.

\section{Experiment 2: validity study}

- The validity values were not high in predicting Single-fallers. The results indicate a sensitivity of $53 \%$ and specificity of $63 \%$ to predict Single-fallers, when the predictor variable was five out of five steps performed correctly.

- The initial analysis found the Multiple-Lunge test to have a sensitivity of $73 \%$ and specificity of $63 \%$ to predict Multiple-fallers, when the predictor variable was five out of five steps performed correctly.

- None of the regression analyses resulted in high values for both sensitivity and specificity.

- Linear regression comparison of Fallers to Non-fallers using steps as the predictor variable resulted in moderate specificity (74\%) with low sensitivity (38\%).

- Linear regression comparison of Multiple-fallers to Non- and Single-fallers using both steps and time variables as predictor variables produced very high specificity (98\%), but low sensitivity (20\%).

\section{Synthesis of the results}

The Multiple-Lunge test was recorded as the number of steps that could be performed correctly for each trial. A step was classified as incorrect if the heel of the foot did not cross the target mark, the participant required assistance (by way of the tester, walking aid, railing or wall), or took more than one step to return to the start position. After a practice trial including two to three familiarisation steps, the individual performed two recorded trials, separated by a rest period to reduce the effects of fatigue. The trial in which the highest number of correct steps was achieved 
was recorded as the score. The score also entailed the total time taken to complete the test.

Consistent with the first hypothesis the Multiple-Lunge test was found to a reliable measure across trials on the same day and different days (ICC $=0.79$ for steps; ICC $=0.86$ for time). ICCs between 0.7 and 0.9 are considered good according to standards set by Fleiss et al. (1986). The change in the mean results for the number of correct steps was similar across the four trials over two testing sessions (-0.43 steps, 0.36 steps, -0.50 steps). However, a slight learning effect may have caused the gradual decrease in time scores across trials, evident by the mean scores and change in mean scores (-0.69 seconds, -0.73 seconds, -0.93 seconds). The Multiple-Lunge test may be used as a pre- and post-test measure to gauge functional improvements as a result of an intervention.

The reliability and validity results may have been affected by limitations in the scoring method or the participants' understanding of instructions. The emphasis in the instructions was on the correct execution of each step, which included the heel of the foot crossing the mark on the floor and performance of the test without support. However, some individuals may have been more concerned with the time score and therefore moved very quickly resulting in a loss of step accuracy for some or all of the steps. This speed-accuracy trade-off may have caused some discrepancy of results. The instructions may be able to be modified to prevent this limitation. Also, natural variation in step length means that it is more difficult to step the same distance for five consecutive steps.

The test-retest reliability results were good, but small modifications to the test procedures may enhance the reliability of the test. The limitations noted in the test procedures included the measurement of leg length which was especially difficult in overweight individuals. An incorrect location of the ASIS would have resulted in an inaccurate leg length measurement and hence step length. Although the mean change in leg length between tests one and two was $-1.43 \mathrm{~cm}$, the mean change in step distance was only $-0.86 \mathrm{~cm}$, which represents a very small difference in actual step distance. However, use of the greater trochanter as a marker instead of the ASIS may be more accurate. The loss of muscle mass in older adults means that this bony landmark should be relatively easy to locate. 
Initial analysis using truth tables used the number of steps done correctly and total time as predictor variables to establish the sensitivity and specificity of the Multiple-Lunge test to predict faller status. This analysis found the predictor variable of five out of five steps done correctly to have a sensitivity of $73 \%$ and specificity $63 \%$ to predict fall status in Multiple-fallers. Logistic regression analysis found only high results for either sensitivity or specificity, but not both. Perell et al. (2001) recommended criteria for establishing 'high' predictive value for fall risk assessment tools as those that sensitivity measures above $80 \%$ and specificity above $70 \%$. However, Oliver et al. (2004) suggested that a $70 \%$ value for sensitivity and specificity is sufficient to indicate a 'high' predictive value. According to these standards the Multiple-Lunge test meets the criteria for sensitivity which supports the second hypothesis to some extent.

Compared to the literature on falls risk assessment tools, the Multiple-Lunge test did not reflect very good validity to predict fallers. However, the studies that achieved the greatest validity results were those involving more frail older adults than the present study. For example, O'Brien et al. (1998) found the BBS to have reduced sensitivity to predict falls in a sample of community-dwelling older adults, than was reported by Berg et al. (1992) with participants of a nursing home. And even with an independent group, some individuals may have greater degrees of impairment. An example of this is a study by Shumway-Cook et al. (1997) which also measured the predictive properties of the BBS. The Faller group comprised individuals who had suffered two or more falls in the previous six months, suggesting higher levels of functional impairment. This may be the reason for the higher validity results (sensitivity $=77 \%$; specificity $=86 \%$ ) reported than those in the present study.

The moderate specificity observed is likely due to a few limitations of the study. Retrospective self-report of falls is not as accurate as prospective monitoring of falls over time. It may be that some Non-fallers should have been classified as Fallers, or some Single-fallers should have been classified as Multiple-fallers. Secondly, the large age range (65 - 93 years) of the subjects may have increased the variability and diversity of the sample. It The occurrence of falls and risk of falls increases with age (Lord et al., 1991), and age-related changes cause a decrease in abilities of balance, reaction time and strength (Sturnieks et al., 2008). Therefore, the older individuals in the sample may have achieved significantly different results to the younger individuals, regardless of fall status. 


\section{Practical applications}

The usefulness of a test may vary depending on the health status and level of function of the individual being tested. The Multiple-Lunge test was developed for assessment of higher functioning older adults, so that subtle weaknesses could be detected. Therefore the test is more challenging than the widely used tests of functional ability for older adults such as the BBS, TUG and 5-STS. The need for a more difficult test, and the high report of trip-type falls in older adults prompted the development of the Multiple-Lunge test. The lunge-type movement is useful with this population as it mimics various kinematic and kinetic aspects of a trip, and the front (support) leg is required to produce the majority of the forces required to regain balance.

The good reliability results imply that the Multiple-lunge test may be a useful tool for assessment of older adults in a research or clinical context. The effects of a programme targeted at reducing falls risk may be measured using the Multiple-Lunge test. It may that improvements in strength, balance, coordination and reaction time are indicated by an increase in the number of correct steps, and/or a decrease in the total time to complete the test. Furthermore, the Multiple-Lunge test is performed relatively quickly with minimal equipment, making it feasible for research and clinical practice.

With regards to the tests validity, the sample of the present study included Single-fallers (contrary to most literature) which accounts for why the test was not sensitive enough to detect differences between these and the Non-faller group. With further research, improvements in the validity of the test may verify the MultipleLunge test as a tool to classify individuals at risk of falls, so that they can be prescribed programmes to reduce falls risk.

\section{Recommendations for future research}

The moderate validity and good reliability results reported for the MultipleLunge test would appear sufficient to warrant further research. Higher predictive values may be achieved by establishing a cut-off score to distinguish between Fallers and Non-fallers. The present study used predictor variables as zero out of five steps and five out of five steps performed correctly. It may be that a cut-off score of three or 
four out of five steps has greater predictive properties. Furthermore, accuracy of time scores could be increased by recording a split time for each test. The recording of time is important to assess the ability to react quickly to a stimulus, a factor affected by age but crucial to preventing a fall on tripping. A split time of each step, as well as the precision of each step would provide the assessor with more information on the functional ability of the participant. Another useful assessment may be the maximum number of correct lunges that can be performed within a certain time. The high level of difficulty of such a test may eliminate the ceiling effects found in other studies, and show greater discrimination between fallers and non-fallers than the present study.

Good reliability results were observed, but these may be increased by making small modifications to the procedures of the test. Very clear instructions need to be given to participants so that step accuracy is enhanced, as well as speed. It may be that measurement of leg length using the greater trochanter as a marker instead of the ASIS is more easily palpated and hence more accurate. This suggested modification may result in even higher reliability results, due to more accurate measurement of leg length. Although test-retest reliability of the Multiple-Lunge test was established, further research is required to determine the inter-rater reliability before it can be used in clinical practice and larger multi-site research studies.

Use of a stronger prospective design in obtaining falls data from the sample may also increase the validity of this test as retrospective self-report is subject to limitations of memory and recall bias. The use of a prospective design in which fall incidence is closely monitored over time may allow a more accurate grouping of individuals and possibly result in higher predictive properties of the Multiple-Lunge test. 


\section{REFERENCES}

Accident Compensation Corporation. (2005). Preventing injuries from falls: the national prevention strategy 2005 - 2015. Retrieved December 2009. from http://www.acc.co.nz/publications/index.

American Geriatrics Society, British Geriatrics Society, \& American Academy of Orthopaedic Surgeons Panel on Falls Prevention. (2001). Guideline for the prevention of falls in older persons. American Geriatrics Society, 49(5), 664-672.

Bandura, A. (1977). Self efficacy - toward a unifying theory of behavioural change. Psychological Review, 84(2), 191-215.

Berg, K. O., Wooddauphinee, S. L., \& Williams, J. I. (1992). Measuring balance in the elderly: validation of an instrument. Canadian Journal of Public Health-Revue Canadienne De Sante Publique, 83, S7-S11.

Berg, W. P., Alessio, H. M., Mills, E. M., \& Tong, C. (1997). Circumstances and consequences of falls in independent community-dwelling older adults. Age Ageing, 26(4), 261-268.

Blake, A. J., Morgan, K., Bendall, M. J., Dallosso, H., Ebrahim, S. B. J., Arie, T. H. D., et al. (1988). Falls by elderly people at home: prevalence and associated factors. Age and Ageing, 17(6), 365-372.

Blennerhassett, J. M., \& Jayalath, V. M. (2008). The Four Square Step Test is a feasible and valid clinical test of dynamic standing balance for use in ambulant people poststroke. Archives of Physical Medicine and Rehabilitation, 89(11), 21562161.

Bogle Thorbahn, L. D., \& Newton, R. A. (1996). Use of Berg Balance Test to predict falls in elderly persons. Physical Therapy, 76(6), 576-583.

Boulgarides, L. K., McGinty, S. M., Willett, J. A., \& Barnes, C. W. (2003). Use of clinical and, impairment-based tests to predict falls by community-dwelling older adults. Physical Therapy, 83(4), 328-339.

Buatois, S., Miljkovic, D., Manckoundia, P., Gueguen, R., Miget, P., Vancon, G., et al. (2008). Five Times Sit To Stand test is a predictor of recurrent falls in healthy community-living subjects aged 65 and older. Journal of the American Geriatrics Society, 56(8), 1575-1577. 
Buchner, D. M., Hornbrook, M. C., Kutner, N. G., Tinetti, M. E., Ory, M. G., Mulrow, C. D., et al. (1993). Development of the common data base for the FICSIT trials. Journal of the American Geriatrics Society, 41(3), 297-308.

Campbell, A. J., Borrie, M. J., Spears, G. F., Jackson, S. L., Brown, J. S., \& Fitzgerald, J. L. (1990). Circumstances and consequences of falls experienced by a community population 70 years and over during a prospective Study. Age Ageing, 19(2), 136-141.

Campbell, A. J., Reinken, J., Allan, B. C., \& Martinez, G. S. (1981). Falls in old age: A study of frequency and related clinical factors. Age Ageing, 10(4), 264-270.

Cummings, S. R., Nevitt, M. C., \& Kidd, S. (1988). Forgetting falls: the limited accuracy of recall of falls in the elderly. Journal of the American Geriatrics Society, 36(7), 613-616.

Davidson, M. (2002). The interpretation of diagnostic tests: A primer for physiotherapists. Australian Journal of Physiotherapy, 48(3), 227-232.

Di Fabio, R. P., Emasithi, A., Greany, J. F., \& Paul, S. (2001). Suppression of the vertical vestibulo-ocular reflex in older persons at risk of falling. Acta OtoLaryngologica, 121(6), 707-714.

Dite, W., Connor, H. J., \& Curtis, H. C. (2007). Clinical identification of multiple fall risk early after unilateral transtibial amputation. Archives of Physical Medicine and Rehabilitation, 88(1), 109-114.

Dite, W., \& Temple, V. A. (2002). A clinical test of stepping and change of direction to identify multiple falling older adults. Archives of Physical Medicine and Rehabilitation, 83(11), 1566-1571.

Duncan, P. W., Weiner, D. K., Chandler, J., \& Studenski, S. (1990). Functional reach: a new clinical measure of balance. Journals of Gerontology, 45(6), M192-M197.

Fife, T. D., \& Baloh, R. W. (1993). Disequilibrium of unknown causes in older people. Annals of Neurology, 34(5), 694-702.

Fitzpatrick, R., \& McCloskey, D. I. (1994). Proprioceptive, visual and vestibular thresholds for the perception of sway during standing in humans. Journal of Physiology-London, 478(1), 173-186.

Fleiss, J. (1986). The design and analysis of clinical experiments. New York: Wiley. 
Fozard, J. L., Vercruyssen, M., Reynolds, S. L., Hancock, P. A., \& Quilter, R. E. (1994). Age differences and changes in reaction time: the Baltimore Longitudinal Study of Ageing. Journals of Gerontology, 49(4), P179-P189.

Friedman, S. M., Munoz, B., West, S. K., Rubin, G. S., \& Fried, L. P. (2002). Falls and fear of falling: Which comes first? A longitudinal prediction model suggests strategies for primary and secondary prevention. Journal of the American Geriatrics Society, 50(8), 1329-1335.

Frontera, W. R., Hughes, V. A., Lutz, K. J., \& Evans, W. J. (1991). A cross-sectional study of muscle strength and mass in 45 to 78 year old men and women. Journal of Applied Physiology, 71(2), 644-650.

Ganz, D. A., Higashi, T., \& Rubenstein, L. Z. (2005). Monitoring falls in cohort studies of community-dwelling older people: effect of the recall interval. Journal of the American Geriatrics Society, 53(12), 2190-2194.

Gill, T., Taylor, A. W., \& Pengelly, A. (2005). A population-based survey of factors relating to the prevalence of falls in older people. Gerontology, 51(5), 340-345.

Gittings, N. S., \& Fozard, J. L. (1986). Age related changes in visual acuity. [Article]. Experimental Gerontology, 21(4-5), 423-433.

Grabiner, M. D., Koh, T. J., Lundin, T. M., \& Jahnigen, D. W. (1993). Kinematics of recovery from a stumble. Journals of Gerontology, 48(3), M97-M102.

Greenwood, K. M. (1999). Measurement: concepts, tools and issues. In V. Minichiello, G. Sullivan, K. Greenwood \& R. Axford (Eds.), Handbook for research methods in health sciences. Sydney: Addison Wesley Longman Australia.

Hanlon, J. T., Landerman, L. R., Fillenbaum, G. G., \& Studenski, S. (2002). Falls in African American and white community-dwelling elderly residents. Journals of Gerontology Series a-Biological Sciences and Medical Sciences, 57(7), M473M478.

Hausdorff, J. M., Rios, D. A., \& Edelberg, H. K. (2001). Gait variability and fall risk in community-living older adults: a 1-year prospective study. Archives of Physical Medicine and Rehabilitation, 82(8), 1050-1056.

Hazell, T., Kenno, K., \& Jakobi, J. (2007). Functional Benefit of Power Training for Older Adults. Journal of Aging \& Physical Activity, 15(3), 349-359.

Hernandez, D., \& Rose, D. J. (2007, May 30-Jun 02). Predicting Which Older Adults Will or Will Not Fall Using the Fullerton Advanced Balance Scale. Paper presented at 
the 54th Annual Meeting of the American-College-of-Sports-Medicine, New Orleans, LA. from $<$ Go to $|S|>: / / 000261803900012$ doi:10.1016/j.apmr.2008.05.020

Hopkins, W. G. (2000). A New View of Statistics. Retrieved November, 2009, from http://newstatsi.org

Hsiao-Wecksler, E. T., \& Robinovitch, S. N. (2007). The effect of step length on young and elderly women's ability to recover balance. Clinical Biomechanics, 22(5), $574-580$

Inouye, S. K., Studenski, S., Tinetti, M. E., \& Kuchel, G. A. (2007). Geriatric syndromes: Clinical, research, and policy implications of a core geriatric concept. Journal of the American Geriatrics Society, 55(5), 780-791.

Kannus, P., Parkkari, J., Koskinen, S., Niemi, S., Palvanen, M., Jarvinen, M., et al. (1999). Fall-induced injuries and deaths among older adults. Jama-Journal of the American Medical Association, 281(20), 1895-1899.

Keskin, D., Borman, P., Ersoz, M., Kurtaran, A., Bodur, H., \& Akyuz, M. (2008). The risk factors related to falling in elderly females. Geriatric Nursing, 29(1), 58-63.

Lakatta, E. G. (2000). Cardiovascular aging in health. Clinics in Geriatric Medicine, 16(3), 419-429.

Lord, S. R. (2006). Visual risk factors for falls in older people. Age and Ageing, 35, 4245.

Lord, S. R., Clark, R. D., \& Webster, I. W. (1991). Physiological factors associated with falls in an elderly population. Journal of the American Geriatrics Society, 39(12), 1194-1200.

Lord, S. R., McLean, D., \& Stathers, G. (1992). Physiological factors associated with injurious falls in older-people living in the community. Gerontology, 38(6), 338346.

Lord, S. R., Murray, S. M., Chapman, K., Munro, B., \& Tiedemann, A. (2002). Sit-tostand performance depends on sensation, speed, balance, and psychological status in addition to strength in older people. Journals of Gerontology Series aBiological Sciences and Medical Sciences, 57(8), M539-M543.

Lord, S. R., Sherrington, C., Menz, H., \& Close, J. (2007). Falls in older people: risk factors and strategies for prevention. Cambridge: Cambridge University Press. 
Lord, S. R., Ward, J. A., Williams, P., \& Anstey, K. J. (1993). An epidemiological study of falls in older community-dwelling women: The Randwick falls and fractures study. Australian Journal of Public Health, 17(3), 240-245.

Lord, S. R., Ward, J. A., Williams, P., \& Anstey, K. J. (1994). Physiological factors associated with falls in older community-dwelling women. Journal of the American Geriatrics Society, 42(10), 1110-1117.

Low, S., Ang, L. W., Goh, K. S., \& Chew, S. K. (2009). A systematic review of the effectiveness of Tai Chi on fall reduction among the elderly. Archives of Gerontology and Geriatrics, 48(3), 325-331.

Marottoli, R. A., Berkman, L. F., \& Cooney, L. M. (1992). Decline in physical function following hip fracture. Journal of the American Geriatrics Society, 40(9), 861866.

McArdle, W. D., Katch, F. I., \& Katch, V. L. (2001). Physical activity, health, and aging. In W. D. McArdle, F. I. Katch \& V. L. Katch (Eds.), Exercise physiology: energy, nutrition, and human performance (5th ed.). Maryland, USA: Lippincott Williams and Wilkins.

Menz, H. B., Morris, M. E., \& Lord, S. R. (2005). Foot and ankle characteristics associated with impaired balance and functional ability in older people. Journals of Gerontology Series a-Biological Sciences and Medical Sciences, 60(12), 1546-1552.

Moreland, J. D., Richardson, J. A., Goldsmith, C. H., \& Clase, C. M. (2004). Muscle weakness and falls in older adults: A systematic review and meta-Analysis. Journal of the American Geriatrics Society, 52(7), 1121-1129.

Muir, S. W., Berg, K., Chesworth, B., \& Speechley, M. (2008). Use of the Berg Balance Scale for predicting multiple falls in community-dwelling elderly people: $A$ prospective study. Physical Therapy, 88(4), 449-459.

Nevitt, M. C., Cummings, S. R., \& Hudes, E. S. (1991). Risk factors for injurious falls: a prospective study. Journals of Gerontology, 46(5), M164-M170.

New Zealand Ministry of Health. (2002). Health of older people in New Zealand: a statistical reference. Retrieved September 2009. from http://www.moh.govt.nz/moh.nsf/wpg Index/PublicationsHealth+of+Older+People+in+New+Zealand+-+A+Statistical+Reference. 
New Zealand Ministry of Health. (2007). Older peoples' health chart book 2006. $\begin{array}{lll}\text { Retrieved } & \text { October } & 2009 .\end{array}$ http://www.moh.govt.nz/moh.nsf/pagesmh/5795/\$̧File/older-peoples-healthchart-book-2006-new.pdf.

Newton, R. A. (1997). Balance screening of an inner city older adult population. Archives of Physical Medicine and Rehabilitation, 78(6), 587-591.

Nordin, E., Lindelof, N., Rosendahl, E., Jensen, J., \& Lundin-Olsson, L. (2008). Prognostic validity of the Timed Up-and-Go test, a modified Get-Up-and-Go test, staffs global judgement and fall history in evaluating fall risk in residential care facilities. Age and Ageing, 37(4), 442-448.

O'Brien, K., Pickles, B., \& Culham, E. (1998). Clinical measures of balance in communitydwelling elderly female fallers and non-fallers. Physiotherapy Canada, 50(3), 212-217.

Oliver, D., Daly, F., Martin, F. C., \& McMurdo, M. E. T. (2004). Risk factors and risk assessment tools for falls in hospital in-patients: a systematic review. Age and Ageing, 33(2), 122-130.

Oloughlin, J. L., Robitaille, Y., Boivin, J. F., \& Suissa, S. (1993). Incidence of and risk factors for falls and injurious falls among the community-dwelling elderly. American Journal of Epidemiology, 137(3), 342-354.

Orr, R., de Vos, N. J., Singh, N. A., Ross, D. A., Stavrinos, T. M., \& Fiatarone-Singh, M. A. (2006). Power training improves balance in healthy older adults. Journals of Gerontology Series a-Biological Sciences and Medical Sciences, 61(1), 78-85.

Pavol, M. J., Owings, T. M., Foley, K. T., \& Grabiner, M. D. (1999). Gait characteristics as risk factors for falling from trips induced in older adults. Journals of Gerontology Series a-Biological Sciences and Medical Sciences, 54(11), M583M590.

Pearson, M. B., Bassey, E. J., \& Bendall, M. J. (1985). Muscles strength and anthropometric indexes in elderly men and women. Age and Ageing, 14(1), 4954.

Perell, K. L., Nelson, A., Goldman, R. L., Luther, S. L., Prieto-Lewis, N., \& Rubenstein, L. Z. (2001). Fall risk assessment measures: an analytic review. Journals of Gerontology Series a-Biological Sciences and Medical Sciences, 56(12), M761M766. 
Pijnappels, M., Bobbert, M. F., \& Van Dieën, J. H. (2005). Push-off reactions in recovery after tripping discriminate young subjects, older non-fallers and older fallers. Gait \& Posture, 21(4), 388-394.

Pijnappels, M., Reeves, N. D., Maganaris, C. N., \& Van Dieën, J. H. (2008). Tripping without falling; lower limb strength, a limitation for balance recovery and a target for training in the elderly. Journal of Electromyography and Kinesiology, 18(2), 188-196.

Pijnappels, M., Van der Burg, J. C. E., Reeves, N. D., \& Van Dieën, J. H. (2008). Identification of elderly fallers by muscle strength measures. European Journal of Applied Physiology, 102(5), 585-592.

Podsiadlo, D., \& Richardson, S. (1991). The Timed Up and Go: a test of basic functional mobility for frail elderly persons. Journal of the American Geriatrics Society, 39(2), 142-148.

Rikli, R. E., \& Jessie Jones, C. (2001). Senior fitness test manual. Champaign: Human Kinetics.

Rinne, M. B., Pasanen, M. E., Miilunpalo, S. I., \& Oja, P. (2001). Test-retest reproducibility and inter-rater reliability of a motor skill test battery for adults. International Journal of Sports Medicine, 22(3), 192-200.

Robertson, M. C., Devlin, M., Scuffham, P., Gardner, M. M., Buchner, D. M., \& Campbell, A. J. (2001). Economic evaluation of a community based exercise programme to prevent falls. Journal of Epidemiological Community Health, 55, 600-606.

Rockwood, K., Awalt, E., Carver, D., \& MacKnight, C. (2000). Feasibility and measurement properties of the Functional Reach and the Timed Up and Go tests in the Canadian Study of Health and Aging. Journals of Gerontology Series a-Biological Sciences and Medical Sciences, 55(2), M70-M73.

Rose, D. J., Lucchese, N., \& Wiersma, L. D. (2003, Mar). Development of a multidimensional balance scale for use with functionally independent older adults. Paper presented at the Joint Conference of the National-Council-onAging/American-Society-on-Aging, Chicago, IL. from <Go to ISI>://000242143500010 doi:10.1016/j.apmr.2006.07.263 
Schaubert, K. L., \& Bohannon, R. W. (2005a). Reliability and validity of three strength measures obtained from community-dwelling elderly persons. Journal of Strength and Conditioning Research, 19(3), 717-720.

Schaubert, K. L., \& Bohannon, R. W. (2005b). Reliability of the Sit-to-Stand test over dispersed test sessions. Isokinetics and Exercise Science, 13(2), 119-122.

Schulz, B. W., Ashton-Miller, J. A., \& Alexander, N. B. (2007). Maximum Step Length: Relationships to age and knee and hip extensor capacities. Clinical Biomechanics, 22(6), 689-696.

Scott, V., Votova, K., Scanlan, A., \& Close, J. (2007). Multifactorial and functional mobility assessment tools for fall risk among older adults in community, homesupport, long-term and acute care settings. Age and Ageing, 36(2), 130-139.

Shumway-Cook, A., Baldwin, M., \& Polissar, N. L. (1997). Predicting the probability for falls in community-dwelling older adults. Physical Therapy, 77(8), 812-819.

Shumway-Cook, A., Brauer, S., \& Woollacott, M. (2000). Predicting the probability for falls in community-dwelling older adults using the Timed Up \& Go Test. Physical Therapy, 80(9), 896-903.

Shumway-Cook, A., Ciol, M. A., Gruber, W., \& Robinson, C. (2005). Incidence of and risk factors for falls following hip fracture in community-dwelling older adults. Physical Therapy, 85(7), 648-655.

Stalenhoef, P. A., Diederiks, J. P. M., de Witte, L. P., Schiricke, K. H., \& Crebolder, H. F. J. M. (1999). Impact of gait problems and falls on functioning in independent living persons of 55 years and over: a community survey. Patient Education and Counseling, 36(1), 23-31.

Statistics New Zealand. (2009). Impact of structural population change. Retrieved. from http://www.stats.govt.nz/publications/populationstatistics/structural-changeand-the-65-population.aspx.

Stevens, J. A., Corso, P. S., Finkelstein, E. A., \& Miller, T. R. (2006). The costs of fatal and non-fatal falls among older adults. Injury Prevention, 12(5), 290-295.

Stone, M. H., Collins, D., Plisk, S., Haff, G., \& Stone, M. E. (2000). Training principles: Evaluation of modes and methods of resistance training. Strength and Conditioning Journal, 22(3), 65-76.

Sturnieks, D. L., St George, R., \& Lord, S. R. (2008). Balance disorders in the elderly. Clinical Neurophysiology, 38(6), 467-478. 
Tager, I. B., Swanson, A., \& Satariano, W. A. (1998). Reliability of physical performance and self-reported functional measures in an older population. Journals of Gerontology Series a-Biological Sciences and Medical Sciences, 53(4), M295M300.

Tanaka, H., \& Seals, D. R. (2008). Endurance exercise performance in Masters athletes: age-associated changes and underlying physiological mechanisms. Journal of Physiology-London, 586(1), 55-63.

Taylor, A. W., \& Johnson, M. J. (2008). Physiology of exercise and healthy aging. Champaign: Human Kinetics.

Thelen, D. G., Schultz, A. B., Alexander, N. B., \& AshtonMiller, J. A. (1996). Effects of age on rapid ankle torque development. Journals of Gerontology Series aBiological Sciences and Medical Sciences, 51(5), M226-M232.

Tiedemann, A., Shimada, H., Sherrington, C., Murray, S., \& Lord, S. (2008). The comparative ability of eight functional mobility tests for predicting falls in community-dwelling older people. Age and Ageing, 37(4), 430-435.

Tinetti, M. E. (1994). Prevention of falls and fall injuries in elderly persons: a research agenda. Preventive Medicine, 23(5), 756-762.

Tinetti, M. E., Deleon, C. F. M., Doucette, J. T., \& Baker, D. I. (1994). Fear of falling and fall-related efficacy in relationship to functioning among community-dwelling elders. Journals of Gerontology, 49(3), M140-M147.

Tinetti, M. E., Liu, W. L., \& Claus, E. B. (1993). Predictors and prognosis of inability to get up after falls among elderly persons. Jama-Journal of the American Medical Association, 269(1), 65-70.

Tinetti, M. E., Speechley, M., \& Ginter, S. F. (1988). Risk-factors for falls among elderly persons living in the community. New England Journal of Medicine, 319(26), 1701-1707.

Tinetti, M. E., \& Williams, C. S. (1998). The effect of falls and fall injuries on functioning in community-dwelling older persons. Journals of Gerontology Series aBiological Sciences and Medical Sciences, 53(2), M112-M119.

Tinetti, M. E., Williams, T. F., \& Mayewski, R. (1986). Fall risk index for elderly patients based on number of chronic disabilities. American Journal of Medicine, 80(3), 429-434. 
Topinkova, E. (2008). Aging, disability and frailty. Annals of Nutrition and Metabolism, 52 (Suppl)(1), 6-11.

Topolski, T. D., LoGerfo, J., Patrick, D. L., Williams, B., Walwick, J., \& Patrick, M. B. (2006). The Rapid Assessment of Physical Activity (RAPA) among older adults. Preventing Chronic Disease: Public Health Research, Practice and Policy, 3(4), 18.

Vellas, B., Cayla, F., Bocquet, H., Depemille, F., \& Albarede, J. L. (1987). Prospective study of restriction of activity in old people after falls. Age and Ageing, 16(3), 189-193.

Voukelatos, A., Cumming, R. G., Lord, S. R., \& Rissel, C. (2007). A randomized, controlled trial of tai chi for the prevention of falls: The central Sydney tai chi trial. Journal of the American Geriatrics Society, 55(8), 1185-1191.

Wall, J. C., Bell, C., Campbell, S., \& Davis, J. (2000). The Timed Get-Up-and-Go test revisited: Measurement of the component tasks. Journal of Rehabilitation Research and Development, 37(1), 109-113.

Whitney, S. L., Marchetti, G. F., Morris, L. O., \& Sparto, P. J. (2004, Feb 04-08). The reliability and validity of the Four Square Step Test for people with balance deficits secondary to a vestibular disorder. Paper presented at the Combined Sections Meeting of the American Physical Therapy Association, Nashville, TN. from <Go to ISI >://000243502000016doi:doi:10.1016/j.apmr.2006.10.027

Whitney, S. L., Wrisley, D. M., Marchetti, G. F., Gee, M. A., Redfern, M. S., \& Furman, J. M. (2005). Clinical measurement of sit-to-stand performance in people with balance disorders: Validity of data for the Five-Times-Sit-to-Stand test. Physical Therapy, 85(10), 1034-1045.

Wild, D., Nayak, U. S., \& Isaacs, B. (1981). How dangerous are falls in old people at home? British Medical Journal, 292(6260), 266-268. 
APPENDICES 
Appendix 1: Ethics approval, Auckland University of Technology Ethics Committee

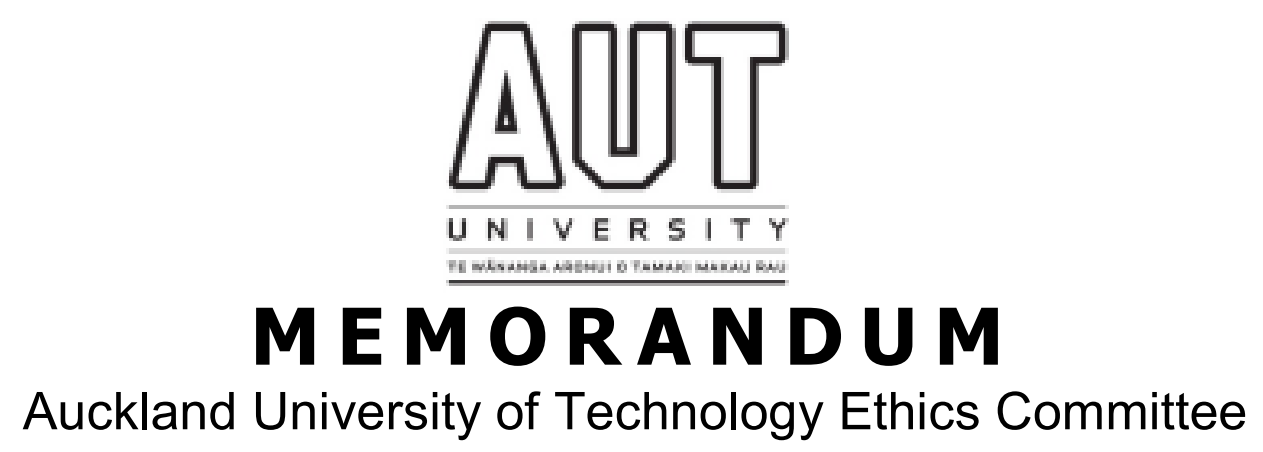

(AUTEC)

To: Justin Keogh

From: $\quad$ Madeline Banda Executive Secretary, AUTEC

Date: 23 June 2009

Subject: Ethics Application Number 09/93 Development of a clinical

Multiple-Lunge test to predict falls in older adults.

Dear Justin

Thank you for providing written evidence as requested. I am pleased to advise that it satisfies the points raised by the Auckland University of Technology Ethics Committee (AUTEC) at their meeting on 11 May 2009 and that the Chair of AUTEC and I have approved your ethics application. This delegated approval is made in accordance with section 5.3.2.3 of AUTEC's Applying for Ethics Approval: Guidelines and Procedures and is subject to endorsement at AUTEC's meeting on 13 July 2009.

Your ethics application is approved for a period of three years until 22 June 2012.

I advise that as part of the ethics approval process, you are required to submit the following to AUTEC:

- A brief annual progress report using form EA2, which is available online through http://www.aut.ac.nz/about/ethics. When necessary this form may also be used to request an extension of the approval at least one month prior to its expiry on 22 June 2012;

- A brief report on the status of the project using form EA3, which is available online through http://www.aut.ac.nz/about/ethics. This report is to be submitted either when the approval expires on 22 June 2012 or on completion of the project, whichever comes sooner; 
It is a condition of approval that AUTEC is notified of any adverse events or if the research does not commence. AUTEC approval needs to be sought for any alteration to the research, including any alteration of or addition to any documents that are provided to participants. You are reminded that, as applicant, you are responsible for ensuring that research undertaken under this approval occurs within the parameters outlined in the approved application. Please note that AUTEC grants ethical approval only. If you require management approval from an institution or organisation for your research, then you will need to make the arrangements necessary to obtain this.

When communicating with us about this application, we ask that you use the application number and study title to enable us to provide you with prompt service. Should you have any further enquiries regarding this matter, you are welcome to contact Charles Grinter, Ethics Coordinator, by email at charles.grinter@aut.ac.nz or by telephone on 9219999 at extension 8860.

On behalf of the AUTEC and myself, I wish you success with your research and look forward to reading about it in your reports.

Yours sincerely

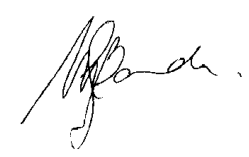

Madeline Banda

Executive Secretary

Auckland University of Technology Ethics Committee

Cc: Ruth Wagenaar rwagenaa@aut.ac.nz, Denise Taylor 
Appendix 2: Participant information sheet

\section{Participant

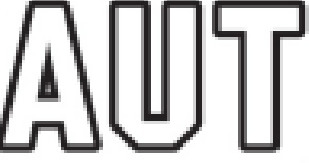 \\ Information Sheet

\section{Date Information Sheet Produced:}

21 April 2009

\section{Project Title}

Development of a clinical Multiple-Lunge test to predict falls in older adults

\section{An Invitation}

You are invited to participate in a study entitled "Development of a clinical Multiple Lunge test to predict falls in older adults". Your participation in this study is completely voluntary and you may withdraw at any time without giving a reason or being disadvantaged in any manner. You may also withdraw any information you have provided at any time up until data collection is completed. The testing will occur at your retirement village.

\section{What is the purpose of this research?}

To develop a new test of physical performance for adults aged 65 years and older. The aim is to assess whether the test is be able to distinguish between individuals who have experienced falls and those who have not.

\section{How was I chosen for this invitation?}

As an older adult in the Auckland region living in a retirement village, you are eligible to participate in this study.

\section{What will happen in this research?}

A Physical Activity Readiness Questionnaire and Falls History Questionnaire, and the Rapid Physical Activity Questionnaire will be conducted, during a telephone call, which will take approximately 20 minutes to complete. After completing this telephone call, you will be asked to attend one testing session. During this session you will perform two functional assessments. These assessments include the Four Square Step Test (FSST) 
and the Multiple Lunge test. The FSST requires you to step in a square pattern into four squares and then in reverse order to where you started. The Multiple Lunge test requires you to step forward with your dominant leg and return to the starting position, for five repetitions. Your leg length will first be measured to establish the distance you need to step. The distance you are required to step will be marked with tape on the floor. A research assistant will stand close by and will be able to help you should you lose your balance. A stopwatch will be used to determine the time taken from the "go" command to return to starting position for both of the functional assessments.

With your consent a video camera will also be used to ensure the timing is accurate and allow analysis of the lunge movement. This part of the study is only required for a few participants, so you may join the study without consenting to be videoed. The camera will be placed at right angles to you, and will record your movement from the 'go' command until the test is completed. Should you wish you will be given an opportunity to view the footage which otherwise will be kept completely confidential. It will only be seen by the researchers, and not be used in any presentation or publication of the results.

\section{What are the discomforts and risks?}

There is some risk of injury when performing the testing activities. There is a possibility that you may lose your balance while performing the tests and this may cause some embarrassment. There is the potential that any embarrassment may be enhanced if you are being video recorded.

\section{How will these discomforts and risks be alleviated?}

You will go through a thorough warm-up prior to the testing sessions. University trained exercise professionals with experience in working with older adults will be with you during the testing session. They will ensure a safe environment, and one in which you feel you can be relaxed and at ease.

\section{What are the benefits?}

The results of this study may have benefits to you as an individual, to other older adults. The results may also help exercise instructors in measuring the success of exercise programmes, and may also be beneficial to mangers of retirement villages. The benefits to you may include:

- You will receive knowledge of how you compare to other adults your age on levels of functional ability. This will give 
you some information that may be helpful in alerting you to possible limitations that you may be beginning to (or have already started) experiencing. With this knowledge, you will be in a position to make a change (if you wish) to your risk of falls.

The results of this study may also have many benefits to other older adults and operators / managers of retirement villages. These may include the following:

- Gerontologists, exercise scientists and agencies like SPARC will be informed on the possible use of a new test of functional ability for older adults, which may be used in later studies to assess the effectiveness of exercise interventions.

- The managers of your retirement village will have more understanding of the level of functional performance and falls risk of their residents. This data will be group data and will not identify your personally though.

\section{What compensation is available for injury or negligence?}

In the unlikely event of a physical injury as a result of your participation in this study, rehabilitation and compensation for injury by accident may be available from the Accident Compensation Corporation, providing the incident details satisfy the requirements of the law and the Corporation's regulations.

\section{How will my privacy be protected?}

After collection of the data, your name will be replaced on the data sheets with an identification code and stored on the primary investigators' computer. The primary investigators will be the only people to have access to the coded data, with this data to be stored on a password-protected computer and in a locked cabinet, respectively. When presenting the results, your name will not be identified.

\section{What are the costs of participating in this research?}

There are generally no costs involved in the participation in this study, except your time commitment. However, if your replies to the Physical Activity Readiness Questionnaire mean that clearance from a medical professional is required for your participation in this project, you will have to pay for this yourself if you wish to participate. As the testing session will occur at your retirement village, you will not need to drive and park your car to participate in this project. The testing session will take approximately one hour. 
What opportunity do I have to consider this invitation?

You will have two weeks to consider your participation in this study.

How do I agree to participate in this research?

You will need to complete the attached Consent Form if you wish to participate in this study.

Will I receive feedback on the results of this research?

If you wish, at the completion of the study you will be sent a copy of your results and a short summary of the results as a whole. No individuals' names will be identified in the summary results. The overall group results of this study will also be submitted for publication in academic journal(s) and for presentation at national / international conference(s). It is usual for there to be a substantial delay between the end of the data collection and publication or presentation of this data in these scientific forums.

What do I do if I have concerns about this research?

Any concerns regarding the nature of this project should be notified in the first instance to the Project Supervisor, Dr Justin Keogh, justin.keogh@aut.ac.nz, 099219999 x7617. Concerns regarding the conduct of the research should be notified to the Executive Secretary, AUTEC, Madeline Banda, madeline.banda@aut.ac.nz, 9219999 ext 8044.

Whom do I contact for further information about this research? \begin{tabular}{|l|l|}
\hline Researcher Contact Details: & Project Supervisor Contact Details:
\end{tabular}

Ruth Wagenaar

Division of Sport and Recreation Auckland University of Technology Private bag 92006

Auckland 1020

Phone: 099219999 ext 7848

Email: rwagenaa@aut.ac.nz
Dr Justin Keogh

Division of Sport and Recreation Auckland University of Technology Private bag 92006 Auckland 1020

Phone: 099219999 ext 7848 Email: justin.keogh@aut.ac.nz

Approved by the Auckland University of Technology Ethics Committee on 23 June 2009, AUTEC Reference number 09/93. 
Appendix 3: Participant consent form

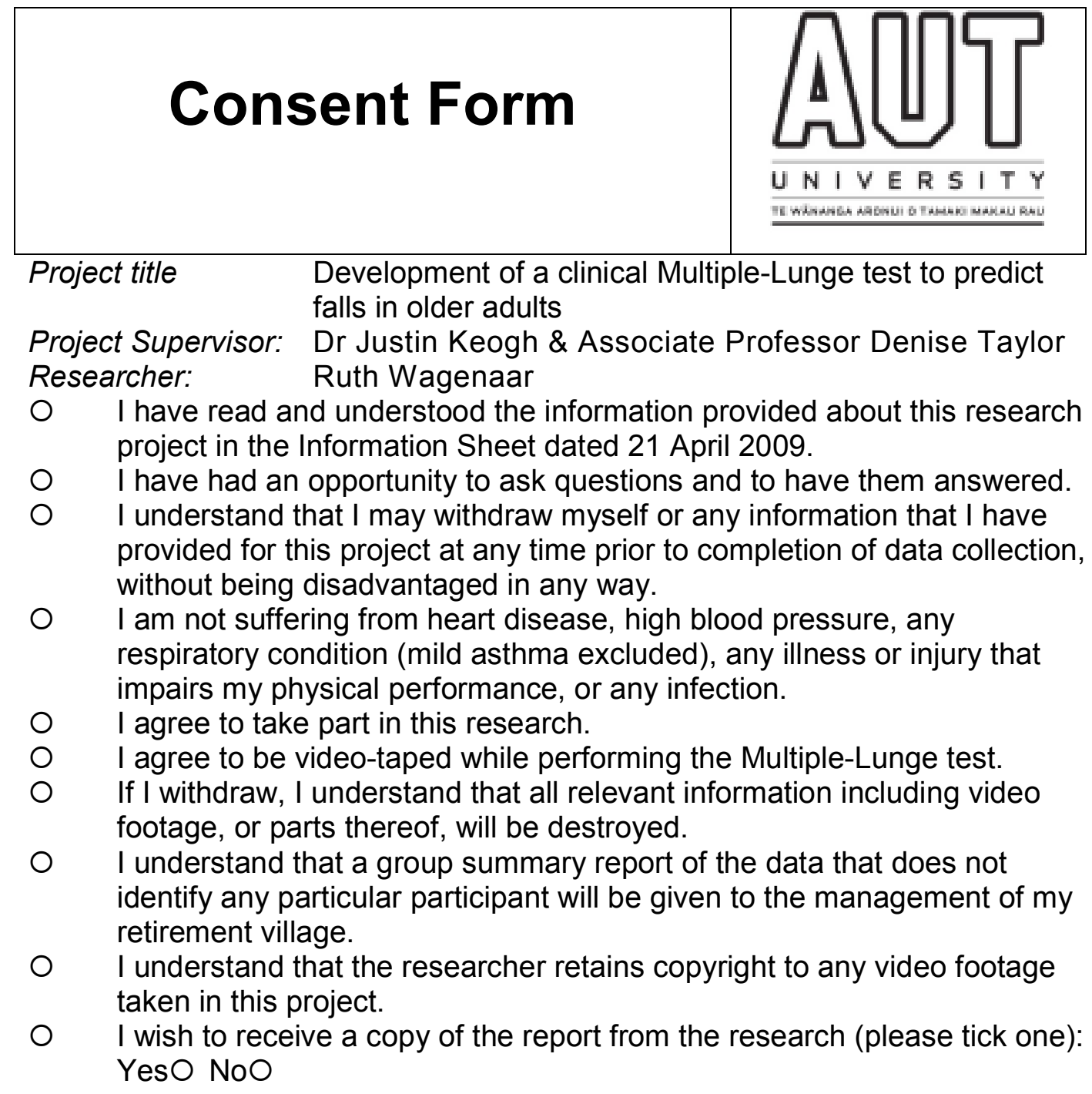

Participant's signature:

Participant's name:

Participant's Contact Details (if appropriate):

Approved by the Auckland University of Technology Ethics Committee on 23 June 2009 AUTEC Reference number 09/93

Note: The Participant should retain a copy of this form 

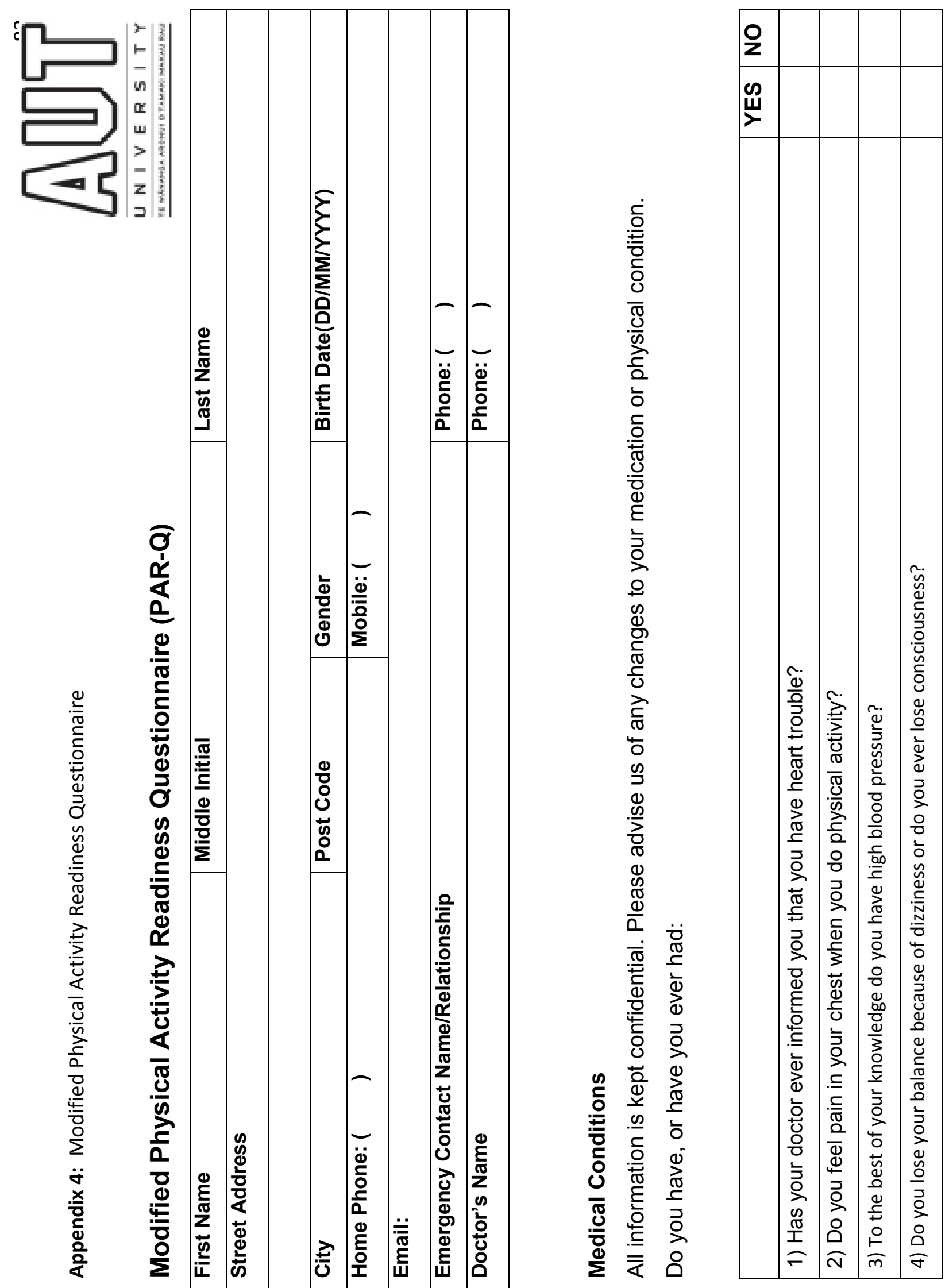


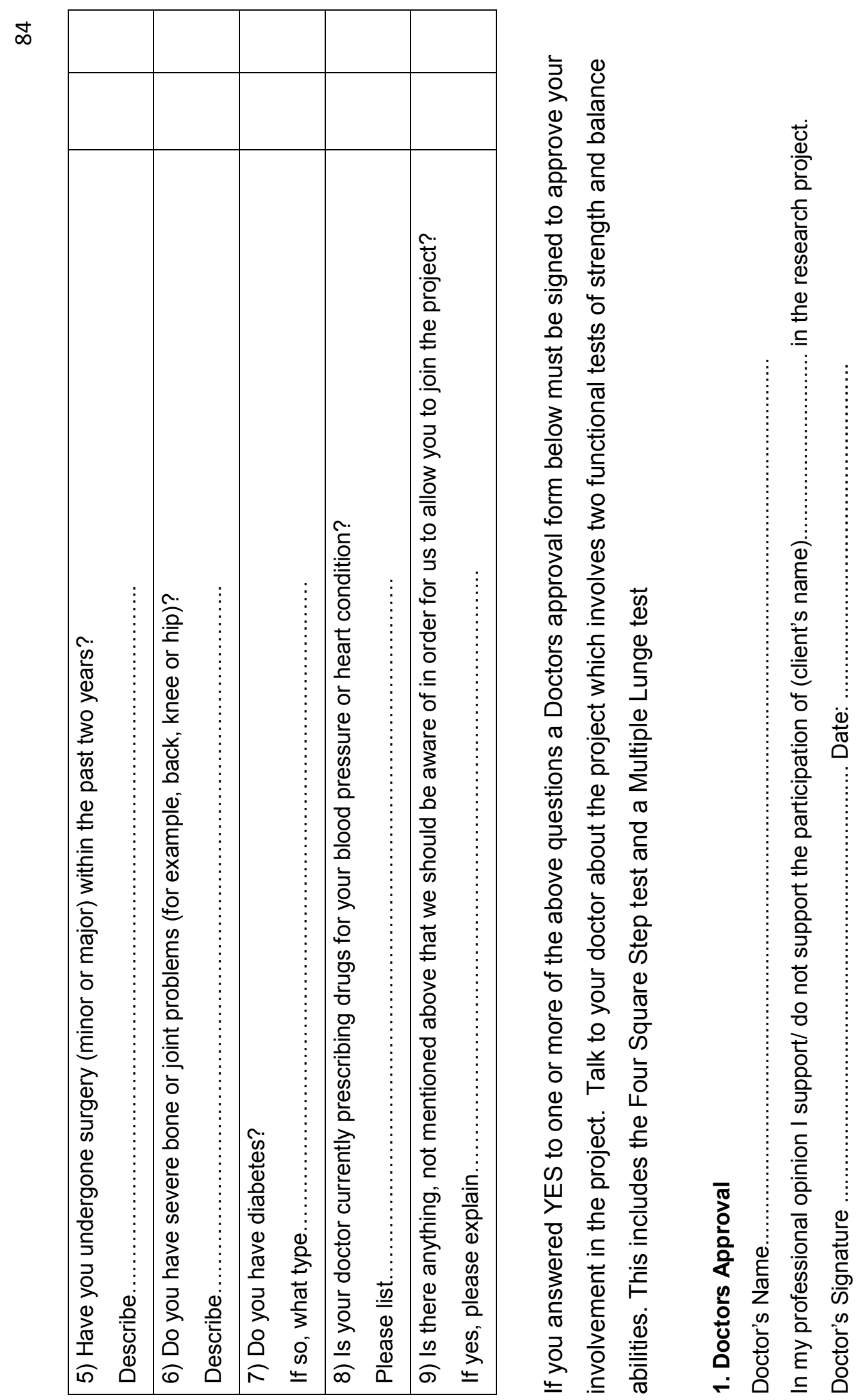


Appendix 5: Falls History Questionnaire

Falls History Questionnaire

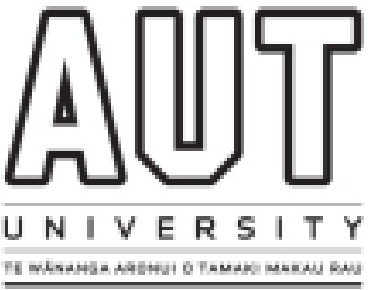

1. Have you fallen in the past 12 months?

A fall is defined as the unintentional event in which you come to rest on the ground, floor or lower level.

2. If you answered YES to the above, how many times have you fallen in the past year?

3. Where and what time did the falls(s) happen?

4. What were you doing at the time of the fall(s)? (e.g. getting up from chair/bed, reaching up or bending down, turning your head).

5. What was the reason for the fall(s)? (e.g. stumble over an obstacle, fall on rising, fall as going down stairs)

6. Did you sustain any injuries as a result of the fall(s)? Yes No If YES, please describe the injury/injuries: 
Appendix 6: Rapid Assessment of Physical Activity (RAPA) Questionnaire

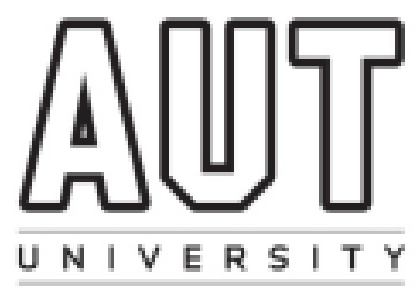

\section{How Physically Active Are You?}

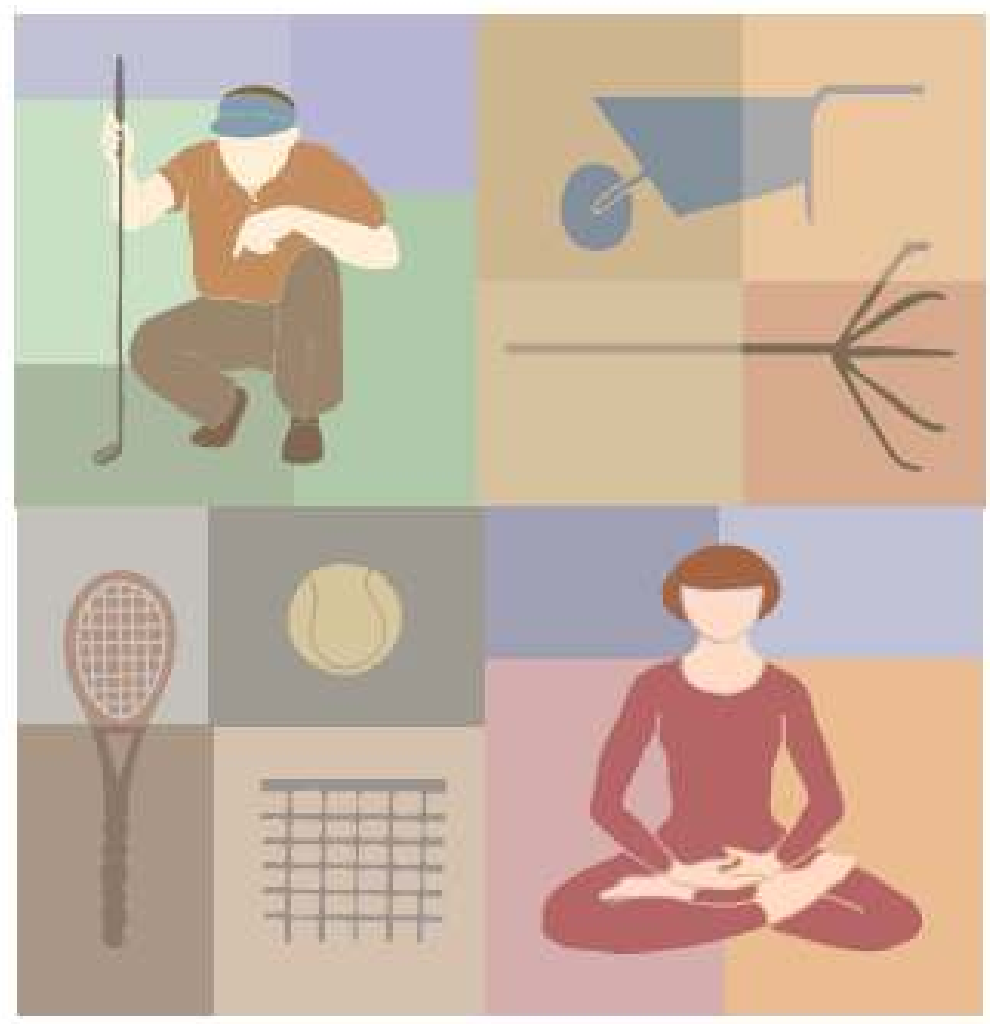

An assessment of level and intensity of physical activity 


\section{Rapid Assessment of Physical Activity}

Physical Activities are activities where you move and increas $\theta$ your heart rate above its resting rate, whether you do them for pleasure, work, or transportation.

The following questions ask about the amount and intensity of physical activity you usually do. The intensity of the activity is related to the amount of energy you use to do these activities.

\section{Examples of physical activity intensity levels:}

Light activities
- your heart beats slightly
taster than normal
- you can talk and sing
$\begin{aligned} & \text { Moderate activities } \\ & \text { - your heart beats faster } \\ & \text { than normal }\end{aligned}$
$\begin{aligned} & \text { you can talk but not } \\ & \text { sing }\end{aligned}$
$\begin{aligned} & \text { - you cant talk or your } \\ & \text { talking is broken up by } \\ & \text { largo broaths }\end{aligned}$


How physically active are you? (Check one answer on each line)

Does this accurately describe you?

\begin{tabular}{|c|c|c|}
\hline I rarely or never do any physical activities. & $\begin{array}{l}\text { Yes } \\
\square\end{array}$ & No \\
\hline $\begin{array}{l}\text { I do some light or moderate physical activities, but not } \\
\text { every week. }\end{array}$ & $\begin{array}{l}\text { Yes } \\
\square\end{array}$ & No \\
\hline I do some light physical activity every week. & $\begin{array}{l}\text { Yes } \\
\square\end{array}$ & $\begin{array}{l}\text { No } \\
\square\end{array}$ \\
\hline $\begin{array}{l}\text { I do moderate physical activities every week, but less } \\
\text { than } 30 \text { minutes a day or } 5 \text { days a week. }\end{array}$ & $\begin{array}{l}\text { Yes } \\
\square\end{array}$ & $\begin{array}{l}\text { No } \\
\square\end{array}$ \\
\hline $\begin{array}{l}\text { I do vigorous physical activities every week, but less } \\
\text { lhidil } 20 \text { mirnules d day or } 3 \text { days a week. }\end{array}$ & $\begin{array}{l}\text { Yes } \\
\square\end{array}$ & $\begin{array}{l}\text { No } \\
\square\end{array}$ \\
\hline $\begin{array}{l}\text { I do } 30 \text { minutes or more a day of moderate physical } \\
\text { activities, } 5 \text { or more days a week. }\end{array}$ & Yes & $\begin{array}{l}\text { No } \\
\square\end{array}$ \\
\hline $\begin{array}{l}\text { I do } 20 \text { minutes or more a day of vigorous physical } \\
\text { activities, } 3 \text { or more days a week. }\end{array}$ & $\begin{array}{l}\text { Yes } \\
\square\end{array}$ & No \\
\hline $\begin{array}{l}\text { I do activities to increase muscle strength, such as } \\
\text { lifting weights or calisthenics, once a week or more. }\end{array}$ & $\begin{array}{l}\text { Yes } \\
\square\end{array}$ & No \\
\hline $\begin{array}{l}\text { I do activities to improve flexibility, such as stretching } \\
\text { or yoga, once a week or more. }\end{array}$ & $\begin{array}{l}\text { Yes } \\
\square\end{array}$ & No \\
\hline
\end{tabular}

NAME:

TODAY'S DATE: 


\section{Scoring Instructions}

\section{RAPA 1: Aerobic}

To score, choose the question with the highest score with an affirmative response. Any number less than 6 is suboptimal.

For scoring or summarizing categorically:

\section{Score as sedentary:}

1. I rarely or never do any physical activities.

Score as under-active:

2. I do some light or moderate physical activities, but not every week.

Score as under-active regular - light activities:

3. I do some light physical activity every week.

Score as under-active regular:

4. I do moderate physical activities every week, but less than 30 minutes a day or 5 days a week.

5. I do vigorous physical activities every week, but less than 20 minutes a day or 3 days a week.

6. Score as active:

7. I do 30 minutes or more a day of moderate physical activities, 5 or more days a week.

8. I do 20 minutes or more a day of vigorous physical activities, 3 or more days a week.

\section{RAPA 2: Strength \& Flexibility}

I do activities to increase muscle strength, such as lifting weights or calisthenics, once a week or more. (1)

I do activities to improve flexibility, such as stretching or yoga, once a week or more. (2)

Both. (3)

None (0) 
Appendix 7: Truth tables for Chapter 3, Validity study. Comparison 1: Percentage of participants with zero out of five steps done correctly.

Truth table comparison of Fallers and Non-fallers for Condition 1 (Percentage of participants with zero out of five steps done correctly)

Faller

Non-faller

Yes No

\begin{tabular}{|ll|ll|}
\hline 25 & $\boldsymbol{a}$ & 13.33 & $\boldsymbol{b}$ \\
\hline 75 & $\boldsymbol{c}$ & 86.67 & $\boldsymbol{d}$ \\
\hline
\end{tabular}

Truth table comparison of Multiple-fallers and Non-fallers for Condition 1 (Percentage of participants with zero out of five steps done correctly)

Multiple-faller

Non-faller Yes No

\begin{tabular}{|ll|ll|}
\hline 40 & $\boldsymbol{a}$ & 13.33 & $\boldsymbol{b}$ \\
\hline 60 & $\boldsymbol{c}$ & 86.67 & $\boldsymbol{d}$ \\
\hline
\end{tabular}


Appendix 8: Truth tables for Chapter 3, Validity study. Comparison 2: Percentage of participants with five out of five steps done correctly.

Truth table comparison of Fallers and Non-fallers for Condition 2 (Percentage of participants with five out of five steps done correctly)

Faller

Non-faller

Yes No

\begin{tabular}{|ll|ll|}
\hline 52.5 & $\boldsymbol{a}$ & 36.67 & $\boldsymbol{b}$ \\
\hline 47.5 & $\boldsymbol{c}$ & 63.33 & $\boldsymbol{d}$ \\
\hline
\end{tabular}

Truth table comparison of Multiple-fallers and Non-fallers for Condition 2

(Percentage of participants with five out of five steps done correctly)

Multiple-faller

Non-faller

Yes No

\begin{tabular}{|ll|ll|}
\hline 73.33 & $\boldsymbol{a}$ & 36.67 & $\boldsymbol{b}$ \\
\hline 26.67 & $\boldsymbol{c}$ & 63.33 & $\boldsymbol{d}$ \\
\hline
\end{tabular}

